\title{
Detached-Eddy Simulation of the Vortical Flowfield about the VFE-2 Delta Wing
}

\author{
Russell M. Cummings ${ }^{*}$ and Andreas Schütte ${ }^{\dagger}$ \\ United States Air Force Academy, Colorado Springs, CO, 80840
}

\begin{abstract}
The numerical simulation of the flow around a $65^{\circ}$ delta wing configuration with rounded leading edges is presented. For the numerical simulation the Cobalt Code uses a cell-centered unstructured hybrid mesh approach. Several numerical results are presented for the steady RANS equations as well as for DES and DDES hybrid approaches. The simulations are done as part of the NATO RTO/AVT 113 working group focusing on experimental and numerical research on delta wing configurations with rounded leading edges. Within this paper the focus is related to the dual primary vortex flow topology, especially the sensitivity of the flow to angle of attack and Reynolds number effects. Reasonable results are obtained with both steady RANS and SA-DDES simulations. The results are compared and verified by experimental data, including surface pressure and pressure sensitive paint results. The impact of transition is assessed, and recommendations for improving future simulations are made.
\end{abstract}

\section{Nomenclature}

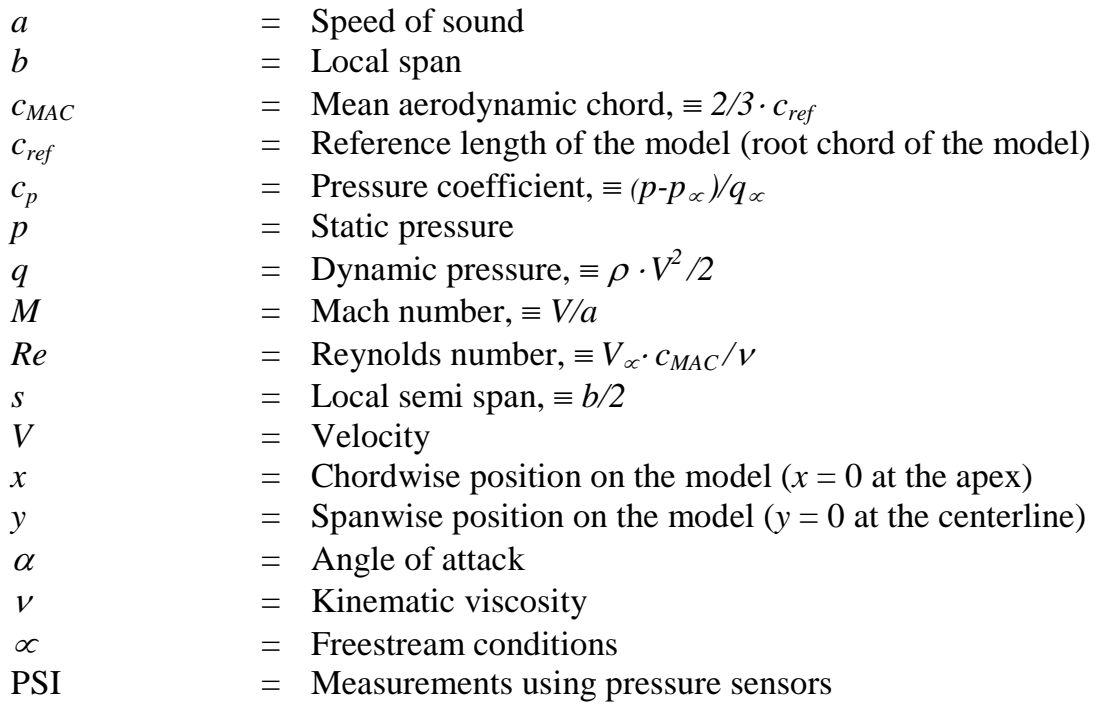

\section{Introduction}

$\mathrm{T}$ HE flow field around delta wing configurations with sharp leading edges is well known, as are approaches to simulating the flow using high fidelity numerical methods. Within the last years several experimental and numerical investigations have been published focusing on the flow topology, Reynolds and Mach number effects, as well as on transition behavior of the vortex dominated flow field around sharp leading-edge delta wings. This is described in detail within publications from the US/European Vortex Flow Experiment $1 .^{1-5}$ The flow around a sharp leading-edge delta wing is characterized by primary vortices initially separating directly at the apex, even at fairly low angles of attack. The shear layer rolls up to form a pair of primary vortices over the wing, with the shear layer formed along the leading edge continuously feeding the vortex down the length of the wing. The secondary vortices

\footnotetext{
*Professor of Aeronautics, AIAA Associate Fellow.

${ }^{\dagger}$ on leave from DLR, Institute of Aerodynamics and Flow Technology, Braunschweig, Germany.
} 
occur due to the interaction of the flow induced by the primary vortex interacting with the boundary layer on the upper wing surface, as seen in Fig. 1. The strength and position of the primary and secondary vortices are mainly influenced by the freestream velocity, angle of attack, as well as on the sweep angle of the delta wing. ${ }^{6,7}$ The vortex flow under turbulent flow conditions is fairly independent of the Reynolds number for sharp leading-edge delta wings, whereas under laminar flow conditions the Reynolds number effects the position and strength of the vortices as well as the vortex topology over the wing. ${ }^{8}$

However, the flow around delta wing configurations with rounded leading edges is still not entirely understood. Therefore the Second International Vortex Flow Experiment - VFE 2 - was established focusing on the flow around delta wing configurations with rounded leading edges. ${ }^{9}$ Several experimental data sets were provided and generated within the NATO RTO/AVT 113 working group for a $65^{\circ}$ swept delta wing with sharp and various blunt/rounded leading edges. The rounded leading edge shapes include low, medium, and high leading edge radii. The experimental data base is used to expand the knowledge about the flow topology and flow physics and to verify and validate computational codes. This paper focuses on the flow topology around the VFE-2 delta wing with medium rounded leading edges at different Reynolds numbers and angles of attack using various turbulence models, especially RANS and hybrid models such as DES and DDES. The overall goal is to understand more fully the flow topology for these non-sharp leading-edge delta wings.

Previous numerical studies on these delta wings have been limited, with Londenberg ${ }^{10}$ showing results for the sharp leading-edge delta wing under transonic conditions and Chiba and Obayashi ${ }^{11}$ performing calculations of the dual primary vortices that form on the medium radius leading-edge. The topology of the dual primary vortices are especially interesting, and form the basis for the majority of papers in two special sessions at the 46th AIAA Aerospace Sciences Meeting and Exhibit.

\section{Numerical Approach}

\section{A. CFD Solver Cobalt}

In this section a brief description of the numerical method is provided. Full details of the computational scheme are presented by Strang et al. ${ }^{12}$ Solutions for all configurations were computed with the commercial version of Cobalt developed by Cobalt Solutions, LLC. Cobalt solves the unsteady, three-dimensional, compressible NavierStokes equations on a hybrid unstructured grid. The code has several choices of turbulence models, including Spalart Allmaras (SA), Spalart Allmaras with Rotation Corrections (SARC), and Menter's Shear Stress Transport (SST) RANS, as well as Detached-Eddy Simulation (DES) and Delayed Detached-Eddy Simulation (DDES) versions of SA, SARC, and SST. All simulations were computed on unstructured meshes with prisms in the boundary layer and tetrahedra elsewhere. The computational meshes were generated with the grid generator Centaur from Centaur-Soft. ${ }^{13}$

\section{B. Turbulence models}

For simulation of turbulent flows, the governing equations are suitably averaged, yielding turbulent stresses that require a turbulence model. A Boussinesq approximation is invoked in the momentum equations and the turbulent eddy viscosity $\left(\mu_{t}\right)$ is used to relate the stresses to the strain rate. The turbulent heat flux is also modeled using a gradient-transport hypothesis, requiring specification of a turbulent thermal conductivity $\left(k_{t}\right)$. The Reynolds analogy is applied and the turbulent heat flux is modeled using a constant turbulent Prandtl number of 0.9. Using turbulent eddy viscosity and turbulent conductivity, the variable, $\mu$, is replaced by $\left(\mu+\mu_{t}\right)$ and $k$ is replaced by $\left(k+k_{t}\right)$ in the governing equations.

\section{Spalart-Allmaras Turbulence Model (SA)}

The Spalart-Allmaras ${ }^{14}$ one equation model (SA) solves a single partial differential equation for a working variable $\tilde{v}$ which is related to the turbulent viscosity. The differential equation is derived by "using empiricism and arguments of dimensional analysis, Galilean invariance and selected dependence on the molecular viscosity." 14 The model includes a wall destruction term that reduces the turbulent viscosity in the laminar sublayer. The model takes the form,

$$
\frac{D \tilde{v}}{D t}=c_{b 1} \tilde{S} \tilde{v}-c_{w 1} f_{w}\left[\frac{\tilde{v}}{d}\right]^{2}+\frac{1}{\sigma}\left[\nabla \cdot((v+\tilde{v}) \nabla \tilde{v})+c_{b 2}(\nabla \tilde{v})^{2}\right]
$$


The turbulent kinematic viscosity is obtained from,

$$
v_{t}=\frac{\mu_{t}}{\rho}=\tilde{v} f_{v 1} ; f_{v 1}=\frac{\chi^{3}}{\chi^{3}+c_{v 1}^{3}} ; \chi=\frac{\tilde{v}}{v}
$$

where $S$ is the magnitude of the vorticity given by

$$
S=|\omega|=|\nabla \times(u \hat{i}+v \hat{j}+w \hat{k})|
$$

and the modified vorticity is,

$$
\tilde{S}=S+\frac{\tilde{v}}{\kappa^{2} d^{2}} f_{v 2} ; f_{v 2}=1-\frac{\chi}{1+\chi f_{v 1}}
$$

where $d$ is the distance to the closest wall. The wall destruction function $f_{w}$ is,

$$
f_{w}=g\left[\frac{1+c_{w 3}^{6}}{g^{6}+c_{w 3}^{6}}\right]^{\frac{1}{6}}
$$

and

$$
g=r+c_{w 2}\left(r^{6}-r\right) ; r \equiv \frac{\tilde{v}}{\tilde{S} \kappa^{2} d^{2}}
$$

The turbulent viscosity is obtained from the turbulent kinematic viscosity by $\mu_{t}=\rho v_{t}$. The model coefficients are given in Table 1.

\begin{tabular}{|c|c|c|}
\hline$c_{b 1}=0.1355$ & $c_{b 2}=0.622$ & $c_{v 1}=7.1$ \\
\hline$\kappa=0.41$ & & $\sigma=2 / 3$ \\
\hline $\begin{array}{c}c_{w 1}=c_{b 1} / \kappa^{2} \\
+\left(1+c_{b 2}\right) / \sigma\end{array}$ & $c_{w 2}=0.3$ & $c_{w 3}=2$ \\
\hline
\end{tabular}

Table 1. Spalart-Allmaras turbulence model coefficients.

\section{Spalart-Allmaras Turbulence Model with Rotation Correction (SARC)}

The turbulence model correction for rotating flows is based on concepts first proposed by Spalart and Shur ${ }^{15}$ as well as Knight and Saffman. ${ }^{16}$ The approach is, "based on tracking the direction of the principal axes of the strain tensor and, thus, is both Galilean invariant and usable in a simple model." ${ }^{17}$ The only difference between SARC and $\mathrm{SA}$ is that in the SARC model the production term in the eddy viscosity transport equation is multiplied by the rotation factor $f_{r 1}$ :

$$
f_{r 1}\left(r^{*}, \tilde{r}\right)=\left(1+c_{r 1}\right) \frac{2 r^{*}}{1+r^{*}}\left[1-c_{r 3} \tan ^{-1}\left(c_{r 2} \tilde{r}\right)\right]-c_{r 1}
$$

If the variables and their derivatives are defined with respect to the rotating reference frame (rotating at rate $\Omega$ ), the non-dimensional quantities $r^{*}$ and $\tilde{r}$ are given by:

$$
\begin{gathered}
r^{*}=S / \omega \\
\tilde{r}=2 \omega_{i k} S_{j k}\left[\frac{D S_{i j}}{D t}+\left(\varepsilon_{j m n} S_{i n}\right) \Omega_{m}\right] / D^{4}
\end{gathered}
$$


where

$$
\begin{gathered}
S_{i j}=0.5\left(\frac{\partial u_{i}}{\partial x_{j}}+\frac{\partial u_{j}}{\partial x_{i}}\right) \\
\omega_{i j}=0.5\left[\left(\frac{\partial u_{i}}{\partial x_{j}}-\frac{\partial u_{j}}{\partial x_{i}}\right)+2 \varepsilon_{m j i} \Omega_{m}\right]
\end{gathered}
$$

and the constants are $c_{r 1}=1.0, c_{r 2}=12$, and $c_{r 3}=1.0$ (see Ref. 17 for details).

\section{Detached-Eddy Simulation (DES)}

The Detached-Eddy Simulation (DES) method was proposed by Spalart et al. ${ }^{18}$ and was originally based on the Spalart-Allmaras one equation RANS turbulence model (detailed above) with a more detailed presentation in Ref. 14. The wall destruction term presented above is proportional to $(\tilde{v} / d)^{2}$, where $d$ is the distance to the wall. When this term is balanced with the production term, the eddy viscosity becomes proportional to $\hat{S} d^{2}$, where $\hat{S}$ is the local strain rate. The Smagorinski Large-Eddy Simulation (LES) model varies its sub-grid scale (SGS) turbulent viscosity with the local strain rate, and the grid spacing: $v_{S G S} \propto \hat{S} \Delta^{2}$, where $\Delta=\max (\Delta x, \Delta y, \Delta z)$. If $d$ is replaced with $\Delta$ in the wall destruction term, the SA model will act as a Smagorinski LES model.

To exhibit both RANS and LES behavior, $d$ in the SA model is replaced by

$$
\tilde{d}=\min \left(d, c_{D E S} \Delta\right)
$$

When $d<<\Delta$, the model acts in a RANS mode and when $d>\Delta$ the model acts in a Smagorinski LES mode. Therefore the model switches into LES mode when the grid is locally refined.

DES was implemented in an unstructured grid method by Forsythe et al. ${ }^{19}$ They determined that the DES constant should be $c_{D E S}=0.65$, consistent with the structured grid implementation of Spalart et al. ${ }^{18}$ when the grid spacing, $\Delta$, was taken to be the longest distance between the cell center and all of the neighboring cell centers.

\section{Delayed Detached-Eddy Simulation (DDES)}

Delayed Detached-Eddy Simulation (DDES) ${ }^{20}$ corrects one of the problems exhibited by DES, namely that the switch between the RANS turbulence model and LES was controlled by the grid spacing. While correct grid spacing could solve this problem for many flows ${ }^{21}$ in cases where the separation is quite shallow (such as a separation bubble over an airfoil), the model often switched in a non-physical manner. To correct this problem, DDES has a switch based on the location of the outer edge of the boundary layer, so that RANS is used within the boundary layer and LES is used outside of the boundary layer. Early results using DDES have shown that the model works very well for flows that are massively or shallowly separated.

\section{Experimental Data}

For the verification and validation of the numerical simulations, various wind-tunnel data have been provided by NASA within the RTO/AVT 113 working group. ${ }^{22}$ Additionally several wind tunnel experiments were done with a 2/3-scaled wind tunnel model loaned by NASA to DLR. ${ }^{23}$ These wind tunnel experiments consist of pressure distribution measurements using pressure taps and Pressure Sensitive Paint (PSP) ${ }^{24}$ as well as measurements of the flow field via Particle Image Velocimetry (PIV). ${ }^{25}$ Figure 2 shows the NASA wind tunnel model in the National Transonic Facility wind tunnel at NASA Langley Research Center. With this model a variety of tests focusing on Reynolds number and Mach number effects were completed. The Reynolds number range is from $6 \cdot 10^{6}$ to $120 \cdot 10^{6}$ at a Mach number of 0.85 , and across a Mach number range of 0.4 to 0.9 at Reynolds numbers of $6 \cdot 10^{6}, 60 \cdot 10^{6}$ and $120 \cdot 10^{6}$. Normal-force and pitching-moment coefficient plots for these Reynolds number and Mach number ranges are also available. These NASA data were given to the working group for code validation from the beginning of the project. $^{26}$ Specifically for the purposes of the AVT-131 working group, DLR measurements with the 2/3-scaled NASA Low-Turbulence Pressure Tunnel (LTPT) model were obtained. Several test campaigns delivered surface pressure data and flow field data for increasing knowledge of the behavior of the rounded leading-edge delta wing 
configuration. Furthermore, the data were given to the working group for computer code validation. Figure 3 shows the pressure distribution over the delta wing measured with PSP, Fig. 4 shows the setup in the Transonic Wind Tunnel in Göttingen to provide the PIV measurements, and Fig. 5 shows an example of a PIV flow field measurement.

\section{Numerical Results and Discussion}

\section{A. Rounded Leading Edge Flow Field}

From the experimental results for the medium rounded leading edge it can be observed that the flow topology over the delta wing is completely different when compared to the flow around the sharp leading-edge configuration. Comparing the flow topology for the sharp leading edge depicted in Fig. 1, the round leading edge generates two primary vortices rotating in the same direction on the upper wing surface (a weaker inner vortex which is apparently generated first and a stronger outer vortex).

The location, strength, and starting point on the upper wing surface vary with Mach number, Reynolds number, and angle of attack. In general, however, the same basic flow topology occurs for all flow conditions. In the following section the numerical capabilities for simulating the flow around the medium rounded leading-edge delta wing will be discussed. Furthermore, the flow physics leading to the described specific flow topology will be discussed and analyzed by use of the computational simulations.

\section{B. RANS Simulation}

In the following section the Reynolds-Averaged Navier-Stokes (RANS) simulation results will be presented. The simulations were done on an IBM P690 system at the Arctic Region Computer Center (ARSC). For the calculations 256 processors were used in parallel. Figures 6 and 7 show the computational unstructured grid. Figure 6 shows the grid resolution on the surface especially in the vicinity of the rounded leading edge. A slice through the mesh at a position $x=$ constant shows the 15 prismatic layers resolving the flow in the boundary layer as well as the field distribution in the spanwise direction. To resolve the flow field on the wing the mesh is pre-refined with a field source in the area where the vortex flow is assumed. The overall grid contains approximately $26 \cdot 10^{6}$ cells or $6 \cdot 10^{6}$ grid points. Figure 7 shows the grid distribution at five $x=$ const. cut planes to show the refinement over the chord of the delta wing. Based on our experience this level of grid density is sufficient for accurate prediction of delta wing flows using other RANS or hybrid turbulence models. ${ }^{26}$

In Figs. 8 and 9 the pressure distributions over the upper wing surface at an angle of attack of $13.3^{\circ}$ for two different Reynolds numbers $\left(2 \cdot 10^{6}\right.$ and $\left.3 \cdot 10^{6}\right)$ are depicted. On the right side the PSP wind tunnel measurements are shown, and on the left side the CFD simulations using the Spalart-Allmaras turbulence model are shown. For both cases the overall flow topology is given correctly by the CFD calculation. The footprint of the inner and outer vortex is predicted by the simulation. One major difference is seen regarding the outer vortex at $\operatorname{Re}_{\mathrm{MAC}}=2 \cdot 10^{6}$. The strength of the outer vortex is predicted too weak by the CFD simulation and too far upstream. For the case of $\mathrm{Re}_{\text {MAC }}=3 \cdot 10^{6}$ the outer vortex also occurs too far upstream, which causes the inner vortex to occur too far outboard. Furthermore, it can be observed that by enhancing the Reynolds number the outer vortex occurs further downstream and the vortex is stronger, causing a higher suction peak on the surface; the inner vortex is getting stronger as well. The same Reynolds number effect can be observed by enhancing the Reynolds number to $4.5 \cdot 10^{6}$ as depicted in Fig. 10. The outer vortex is generated further downstream and the effect of the inner vortex on the surface pressure distribution is far more downstream towards the trailing edge.

The discussion to this point has focused on the quality of the CFD results; we will now take a look at the results quantitatively. In Figs. 11 and 12 the related PSI pressure tap distributions at five $x=$ constant positions are depicted. On the left side the experimental PSI pressure tap data are shown, and on the right side the CFD simulations are shown. It is seen that besides the correct representation of the flow topology by the CFD simulation there are some differences in the pressure levels. In Fig. 11 for the Reynolds number of $2 \cdot 10^{6}$ it can be observed that the flow is initially attached around the leading edge and over the span at $20 \%$ chord length. The suction peak directly at the leading edge is predicted too high by the CFD simulation (note, however, that the experimental data points are fairly widely spaced compared with the CFD cell size). The suction peak of the outer vortex at $40 \%$ and $60 \%$ chord length is represented too weak by the simulation as mentioned previously. The distribution at the other positions at $80 \%$ and $95 \%$ are predicted a bit too strong. The spanwise position of the outer vortex is given correctly by the CFD simulation. The strength of the suction peak of the inner vortex at $40 \%$ chord length is represented quite well by the 
simulation but too far outboard. The position and strength of the inner vortex depends on the position of its origin as well as on the strength and position of the outer vortex making this especially difficult to compute since it is based on the prediction of separation near the apex of the wing. Also, there might be transition effects for this case which will be discussed later on.

In Fig. 12 the situation at a Reynolds number of $3 \cdot 10^{6}$ is depicted. As mentioned before enhancing the Reynolds number leads to a generation of the outer vortex further downstream. The flow around the leading edge is attached over the whole span up to $40 \%$ chord length. The suction peak at the leading edge at $20 \%$ chord length is predicted correctly when compared with the experiment whereas the suction peak at $40 \%$ is predicted too high. The inner vortex occurs more upstream in the experiment as identified by the suction peak at $65 \%$ span wise position approximately. In the simulation there is no suction peak observed at this position. At $60 \%$ chord length the inner vortex suction peak can be observed, but it is weaker and further inboard as compared with the experiment. One reason for a weaker and more inboard suction peak of the outer vortex at $60 \%$ chord length might be related to the fact that the inner vortex in this case is generated too far upstream at the leading edge in comparison to the experiment. This can also be observed in Fig. 9. The suction peak of the outer vortex is predicted too high at $80 \%$ and $95 \%$ chord length in the same way as in the case at a Reynolds number of $2 \cdot 10^{6}$. However the vortex occurs more upstream, although the span wise position is given correctly at $80 \%$ and $95 \%$ chord length. But this could be more or less fortuitous because the balance of the vortex strength between the inner and the outer vortex is very sensitive to several factors which will be discussed later on.

Due to the fact that there are several differences between the experiment and the simulation, some sensitivity factors that may influence the numerical solution should be discussed. These factors are, among others, the selected turbulence model, the angle of attack and Reynolds number effects. Finally, the effect of transition is a factor which could influence the flow topology. Even if it is not correct to compare CFD simulations with experimental results under different conditions, it should show that small changes in the flow field could have a large effect on the flow topology. Particularly we are not taking the wind tunnel surroundings into account within the CFD which could have a big influence on the flow conditions. ${ }^{16}$ In the following discussion some of these sensitivities will be discussed.

The Reynolds number effect was discussed previously. In Fig. 13 the results at Reynolds number $3 \cdot 10^{6}$ and $4.5 \cdot 10^{6}$ are compared. As described before, if we increase the Reynolds number the outer vortex occurs further downstream. Comparing the PSP results at Reynolds number $3 \cdot 10^{6}$ with the CFD solution at $4.5 \cdot 10^{6}$ in Fig. 14 and 15 it can be observed that the pressure distribution of the outer vortex fits better with the experiment than in the case of $3 \cdot 10^{6}$ Reynolds number. The outer vortex is generated at nearly the same position as in the experiment as seen in Fig. 14. Figure 15 shows an even better agreement compared with the quantitative results. The suction peak of the outer vortex at $60 \%$ chord fits well with the experiment. Nevertheless, the inner vortex is too weak as well as in the direct comparison with the $3 \cdot 10^{6}$ Reynolds number simulation. But the location of the inner vortex in case $4.5 \cdot 10^{6}$ is more inboard and occurs further downstream which fits better with the experiment at $3 \cdot 10^{6}$. These results should show how sensitive the flow topology is to small Reynolds number changes.

The simulations in Fig. 16 at a Reynolds number of $\operatorname{Re}_{\mathrm{MAC}}=6 \cdot 10^{6}$ should give an example of the angle of attack effect on the flow topology over the wing. Compared to the Reynolds number effect, the effect of enhancing the angle of attack has the opposite effect. Increasing the angle of attack causes the generation of the outer vortex to move upstream. The same thing happens to the inner vortex. Due to the outer vortex location and enhanced strength, the inner vortex is pushed inboard. Figures 17, 18, and 19 show the comparison between PSI data on the left hand side and CFD calculation on the right hand side. For the experimental data it has to be taken into account that the spanwise data at $\mathrm{y} / \mathrm{s}=0.675$ is sparse out in this region. Comparing Figs. 17 and 18 in case of $\alpha=13.3^{\circ}$ and $18.4^{\circ}$ it can be observed in the experimental data that the suction peak of the inner vortex stays constant for increasing the angle of attack, even though the suction peak of the outer vortex grows. The same can be observed in the simulation but far more downstream. The outer vortex seems to occur too far downstream in the simulation. This leads to the fact that the suction peak of the inner vortex can be observed at $x / c_{\text {ref }}=0.8$ for the angle of attack of $\alpha=13.3^{\circ}$ and at $\mathrm{x} / \mathrm{c}_{\text {ref }}=0.4$ for the angle of attack of $\alpha=18.4^{\circ}$. As with the other simulations discussed before, the strength of the inner vortex is given too weak by the simulation. Finally the simulation at $\alpha=23^{\circ}$ fits quite well with the experiment since the flow topology is well established and less sensitive at this higher $\alpha$.

In nearly all computational simulations the inner vortex is predicted too weak and the question arises as to which boundary condition influences the generation of the inner vortex. For the final RANS simulation the production of turbulence is set to zero up to $10 \%$ of the centerline chord. Even though a real transition line is much more complicated on the delta wing surface, this transition line should show if there is an influence. Figure 20 shows the comparison of the pressure distribution between the case with and without transition. Besides the bending of the contour lines at the apex, no significant change in the overall pressure distribution can be observed. Regarding the 
pressure distribution in Fig. 21 it can be observed that there is an effect at $20 \%$ chord length. But there is no influence on the flow topology further downstream. The transition setting probably leads to a thicker boundary layer at the apex but is not influencing the generation of the inner vortex significantly. Furthermore, the implementation of the non-slip boundary condition in a region of high surface curvature might have an influence on the transition behavior and should be investigated.

\section{DES and DDES Simulation}

The use of Detached-Eddy Simulation (DES) has traditionally been reserved for massively separated, or at the very least, unsteady flow fields. Steady vortical flows are often well predicted with modern RANS turbulence models and often do not require the use of DES. The unusual nature of the flow around the blunt leading edge delta wing, however, makes the use of DES a possible candidate for flow prediction in this case. The shallow nature of the flow features on the front half of the wing (as seen in Fig. 5), can also give DES a difficult challenge, since flow features close to a surface can be poorly predicted with traditional DES, so Delayed Detached-Eddy Simulation (DDES) will also be used to simulate this flow.

The first simulation using DES used SA with a Rotation Correction (SARC-DES). SARC has been shown to work well for vortical flows in conjunction with DES (Ref. 26). Surface pressures using SARC-DES are compared with experimental PSP measurements in Fig. 22. The numerical simulation shows the inner and outer primary vortices forming too far upstream, and the outer vortex shows signs of unusual behaviour as the vortex wanders inboard and outboard as it convects toward the trailing edge. There is no evidence that the solution is unsteady except near the trailing edge, which does not explain the vortex wandering. Figure 23 shows a comparison of surface pressures with the PSI data, and the early formation of the vortices is confirmed. By $20 \%$ of the chord the inner and outer vortices have formed, contrary to the experimental data which shows only early signs of the formation of the inner vortex at this chordwise station. Because the vortices form too early, the downstream position of both the inner and outer vortices is too far outboard, and the inner vortex is too weak when compared with the experimental data.

Due to the shallow nature of the vortices (especially the inner vortex), it was decided to try DDES on this configuration in conjunction with SARC, as shown in Figs. 24 and 25. While the surface pressure map for SARCDDES shown in Fig. 24 is much better than the SARC-DES prediction in Fig. 22, the remainder of the prediction is in fact very similar to the SARC-DES prediction. The vortices again form too early (as shown in both Figs. 24 and 25 ) and the position and strength of the vortices are not greatly improved over the SARC-DES simulation.

Since the previous applications of DES and DDES were not as successful as hoped, a further simulation was performed using the basic Spalart-Allmaras turbulence model (SA) in conjunction with DES (labelled SA-DES). The surface pressure map and pressure comparisons with experimental data are presented in Figs. 26 and 27, respectively. The surface pressure map in Fig. 26 shows signs of the vortex wandering similar to the SARC-DES simulation in Fig. 22, the surface pressures are in better agreement with the experimental data than the previous simulations. Specifically, Fig. 27 shows that there is no significant vortex generation at $x / c_{\text {ref }}=0.2$, although a region of decreased pressure is evident near $\mathrm{y} / \mathrm{s}=0.4$, which is very similar to the experimental trend. Also, by $\mathrm{x} / \mathrm{c}_{\mathrm{ref}}$ $=0.6$, both an inner and outer vortex have formed, although the secondary vortex near the leading edge is different than the experiment, and the location of the outer vortex is also incorrectly predicted. The inner and outer vortex positions are consistent as the flow convects downstream, with small differences in vortex strength and position noted.

The improvement shown by the SA-DES solution, coupled with the relative success of the SARC-DDES solution, led to a final simulation using SA-DDES. The surface pressure map is shown in Fig. 28, while the pressure comparison with experimental data is shown in Fig. 29. The simulated flow field using SA-DDES is significantly improved over any of the other previous hybrid turbulence model simulations. The formation of the inner and outer vortices matches the experimental data quite well, and the position and strength of the vortices is as close to the experiment as with the other simulations presented. While the suction peak seems higher than the experimental data, the experimental pressure taps were fairly widely spaced in this region, making it difficult to determine the precise suction peak from the experiment. The main differences between the predictions and experimental data lie near the trailing edge of the delta wing, however the simulations showed that the vortices were unsteady in this region, and a sufficiently high time averaging may improve the predictions in this region. The SA-DDES probably has performed the best because of the ability of DDES to properly transition from RANS to LES without being influenced by the local grid refinement, coupled with the performance of SARC in the leading-edge region of the delta wing, where large flow curvature exists that is not associated with vortices. 


\section{Discussion of Flow Topology}

The rounded leading-edge delta wing yields an interesting and complex flow topology which is only marginally understood at this time. While the experimental results shown in Fig. 5 are helpful in understanding the flow, the necessary limitations of the experiments (such as the number of axial locations where PIV measurements were made) make it difficult to fully understand the flow field. The experimental predictions, in conjunction with the numerical simulations, can begin to form a fuller picture of the flow.

Figures 30 and 31 show a representative solution of the flow field with surface pressure maps, $x$-vorticity contours, and streamlines, while Fig. 32 shows the skin friction lines for the flow, which add another layer of information for understanding what is happening with this configuration. The $x$-vorticity contours in Fig. 30 show that a region of vorticity near the surface of the delta wing exists at $x / c_{r e f}=0.2$. This is the same region that was noted upstream of the formation of the inner and outer vortices in previous simulations using RANS and SA-DES. Examination of the flow in the region of vorticity at $\mathrm{x} / \mathrm{c}_{\mathrm{ref}}=0.2$ have shown that there is no reversed flow present, and no noticeable boundary layer separation has taken place. Further investigation into the boundary layer profile at $\mathrm{x} / \mathrm{c}_{\mathrm{ref}}=0.2 \mathrm{might}$ aid in a fuller understanding of the flow topology. At $\mathrm{x} / \mathrm{c}_{\text {ref }}=0.3$ the two primary vortices have clearly formed, but it is not obvious which vortex formed first and how the formation of the vortices is impacted by the upstream low pressure/higher vorticity region. Figure 31 shows the streamlines created by releasing particles near the surface along the leading edge of the delta wing. Flow around the apex and near the centerline of the wing stays attached along the entire length of the wing, but after a short distance along the leading edge there is flow separation that rolls up into the inner vortex. There is a critical point along the leading edge where the separating flow no longer feeds the inner vortex, but rather begins to feed the outer vortex. Since the inner vortex is no longer being fed vorticity from the leading edge shear layer, it does not continue to grow in size or strength as it convects downstream. The outer vortex, however, continues to gain vorticity from the shear layer and grows in size and strength down the remainder of the delta wing length.

The combined information from Figs. 30 and 31, coupled with the skin friction lines of Fig. 32, show a more comprehensive picture of the formation of the dual primary vortex system. A separation line is evident along the leading edge, but it does not extend to the apex of the wing. This coincides with the attached flow along the centerline of the wing. Once the separation line forms, a shear layer convects over the upper surface of the delta wing. A region of flow near the wing surface, corresponding to the region of lower pressure/higher vorticity mentioned above, is diverted outboard to the location where the outer primary vortex is formed. The outboard flow is possibly caused by the rotation of the shear layer that is flowing above this region; the shear layer eventually rolls up into the inner primary vortex. It is possible that the surface flow which is forced outboard is the cause of the critical point where the outer primary vortex is formed, although more detailed investigation is warranted to more fully understand this complex flow region.

\section{Conclusions}

In this paper the results of CFD calculation with the unstructured Cobalt code are presented. Numerical simulations for flow around a rounded leading-edge delta wing with $65^{\circ}$ of sweep are performed using RANS, DES, and DDES turbulence models. Comparisons with available experimental data, including surface pressures, pressure sensitive paint, and particle image velocimetry, show that a reasonable simulation of this flow field can be made with RANS turbulence models, although the SA-DDES model showed promise for gaining a fuller understanding of the flow field. As usual, researchers should use the level of modeling that is appropriate for the level of detail required for a given application; the expense and computer resources required for hybrid turbulence models may not be warranted for every application.

The numerical simulations have led to an increased understanding of the flow field for the round leading-edge delta wing, especially for the formation of the dual primary vortex system. A proposed mechanism for the formation of the dual primary vortex system is given based on various surface and off-surface flow visualizations. A complex flow topology exists due to the rounded leading edge, including an initial shear layer that induces flow underneath the formation of the inner vortex that eventually causes the inner vortex to be cut off from the shear layer. This leads to the formation of the outer primary vortex, while the inner primary vortex is cut off from the shear layer and stops growing in size or strength.

Designers of various aircraft that might use rounded leading edges on highly swept wings will have to more fully understand the complexities of the dual primary vortex system, and how the vortex system is influenced by sweep angle, leading edge radius, and freestream conditions (such as Reynolds number, Mach number, and angle of attack). 


\section{Acknowledgments}

The authors would like to thank Dr. Robert Konrath of DLR and Dr. James Luckring from NASA Langley Research Center for providing the wind tunnel data. Computer time was made available by the DoD High Performance Computer Modernization Program, for which we are grateful. We are also grateful to the Modeling \& Simulation Research Center at the Air Force Academy for their support. In addition, we would like to thank Prof. Dietrich Hummel for his guidance of the VFE-2 facet of the NATO RTO/AVT-113 working group.

\section{References}

1 Drougge, G., “The International Vortex Flow Experiment for Computer Code Validation,” ICAS Proceedings, 1988 , Vol. 1, pp. 35-41.

Elsenaar, A., Hjelmberg, L., Bütefisch, K.-A., and Bannink, W.J., "The International Vortex Flow Experiment." AGARD-CP 437, 1988, Vol.1, pp. 9-1 to 9-23.

3 Wagner, B., Hitzel, S., Schmatz, M.A., Schwarz, W., Hilgenstock, A., and Scherr, S., "Status of CFD Validation on the Vortex Flow Experiment," AGARD-CP 437, 1988, Vol. 1, pp. 10-1 to 10-10.

4 Hoeijmakers, H.W.M., "Modelling and Numerical Simulation of Vortex Flow in Aerodynamics," AGARD-CP 494, 1991, pp. $1-1$ to $1-46$.

5 Luckring, J.M., "Recent Progress in Computational Vortex-Flow Aerodynamics," AGARD CP 494, 1991, pp. 6-1 to 621.

6 Hummel, D., „Zur Umströmung scharfkantiger schlanker Deltaflügel bei großen Anstellwinkeln,“ Z. Flugwiss. Vol. 15, 1967, pp. 376-385.

7 Hummel, D., „Experimentelle Untersuchung der Strömung auf der Saugseite eines Deltaflügels,“ Z. Flugwiss. Vol. 13, $1965,247-252$.

8 Hummel, D., "Effects of Boundary Layer Formation on the Vortical Flow above Slender Delta Wings," Proceedings of the I MECH E Part G, Journal of Aerospace Engineering, Vol. 220, No. 6, 2006 , pp. 559-568.

9 Hummel, D., Redeker, G., “A New Vortex Flow Experiment for Computer Code Validation,” RTO-AVT Symposium on Vortex Flow and High Angle of Attack, Loen Norway, May 7-11, 2001.

10 Londenberg, W.K., "Transonic Navier-Stokes Calculations about a 65 deg Delta Wing," NASA Contractor Report, NASA-CR-4635, Nov. 1994.

11 Chiba, K., Obayashi, S., "CFD Visualization of Second Primary Vortex Structure on a 65-Degree Delta Wing," AIAA Paper 2004-1231, Jan. 2004.

12 Strang, W.Z., Tomaro, R.F., Grismer, M.J., "The Defining Methods of Cobalt: A Parallel, Implicit, Unstructured Euler/Navier-Stokes Flow Solver,” AIAA Paper 99-0786, Jan. 1999.

13 Centaur Soft: http://www.Centaursoft.com

14 Spalart, P.R., Allmaras, S.R., "A One Equation Turbulence Model for Aerodynamic Flows,” La Recherche Aerospatiale, Vol. 1, 1994, p. 5.

15 Spalart, P.R., Shur, M.L., "On the Sensitization of Turbulence Models to Rotation and Curvature," Aerospace Science and Technology, Vol. 1, No. 5, 1997, pp. 297-302.

16 Knight, D.D., Saffman, P.C., "Turbulence Model Predictions for Flows with Significant Mean Streamline Curvature," AIAA Paper 78-0258, Jan. 1978.

17 Shur, M.L., Strelets, M.K., Travin, A.K., Spalart, P.R., "Turbulence Modeling in Rotating and Curved Channels: Assessing the Spalart-Shur Correction,” AIAA Journal, Vol. 38, No. 5, 2000, pp. 784-792.

18 Spalart, P. R. , Jou W-H. , Strelets M., Allmaras, S. R., "Comments on the Feasibility of LES for Wings, and on a Hybrid RANS/LES Approach," Advances in DNS/LES, 1st AFOSR Int. Conf. on DNS/LES, Aug 4-8, 1997, Greyden Press, Columbus Oh.

19 Forsythe, J.R., Hoffmann, K.A., Dieteker, F.F., "Detached-Eddy Simulation of a Supersonic Axisymmetric Base Flow with an Unstructured Flow Solver," AIAA Paper 2000-2410, June 2000.

20 Spalart, P.R., Deck, S., Shur, M.L., Squires, K.D., Strelets, M.K., Travin, A., "A New Version of Detached-Eddy Simulation, Resistant to Ambiguous Grid Densities," Theoretical and Computational Fluid Dynamics, Vol. 20, 2006, pp. 181-195.

${ }^{21}$ Spalart, P.R., "Young Person's Guide to Detached-Eddy Simulation Grids,” NASA CR 2001-211032, July 2001.

22 Chu, J. and Luckring, J.M., "Experimental Surface Pressure Data Obtained on $65^{\circ}$ Delta Wing Across Reynolds Number and Mach Number Ranges," NASA Technical Memorandum 4645, Vol 1-4, 1996.

${ }_{23}$ Konrath, R., Klein, C., Engler, R.H., Otter, D., "Analysis of PSP Results Obtained for the VFE-2 $65^{\circ}$ Delta Wing Configuration at Sub- and Transonic Speeds,” AIAA Paper 2006-60, Jan. 2006.

24 Klein, C., Sachs, W.E., Henne, U., Engler, R.H., Wiedemann, A., Konrath, R., "Development of PSP Technique for Application on the VFE-2 65 Delta Wing Configuration," AIAA Paper No 2006-59, Jan. 2006.

${ }^{25}$ Konrath, R., Schröder, A., Kompenhans, J., "Analysis of PIV Results Obtained for the VFE-2 $65^{\circ}$ Delta Wing Configuration at Sub- and Transonic Speeds,” AIAA Paper No 2006-3003, June 2006.

${ }_{26}$ Mitchell, A.M., Morton, S.A., Forsythe, J.R., Cummings, R.M., "Analysis of Delta-Wing Substructures Using DetachedEddy Simulation,” AIAA Journal, Vol. 44. No. 5, 2006, pp. 964-972. 


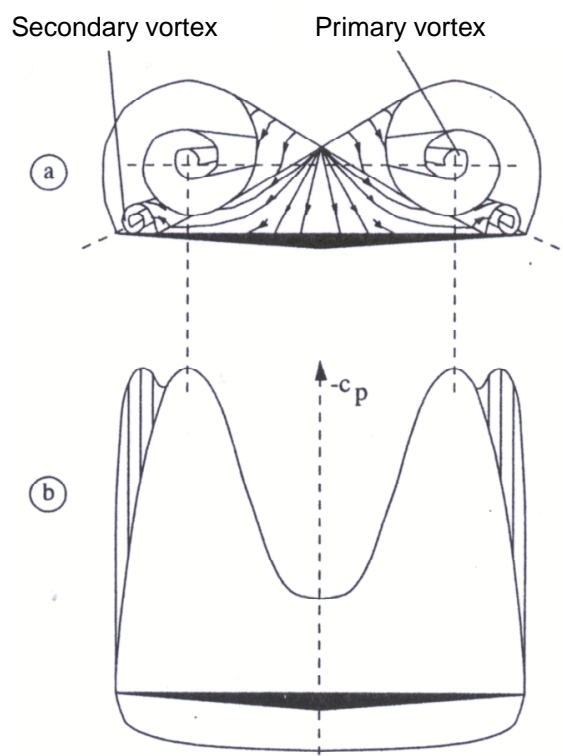

Figure 1: Schematic view of the flow over a sharp edged delta wing:

a) vortex formation

b) pressure distribution in a cross section. $^{7}$

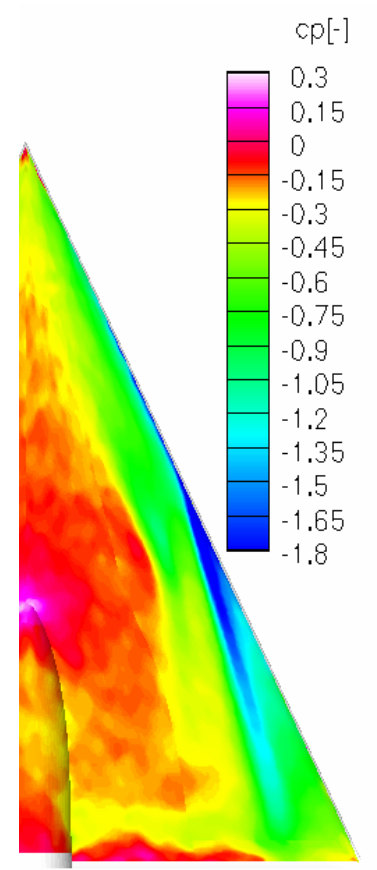

Figure 3: Pressure distribution on the upper side of the wing using PSP

(Pressure Sensitive Paint). $M=0.4$, $\operatorname{Re}=3 \cdot 10^{6}, \alpha=14^{\circ} .{ }^{13}$

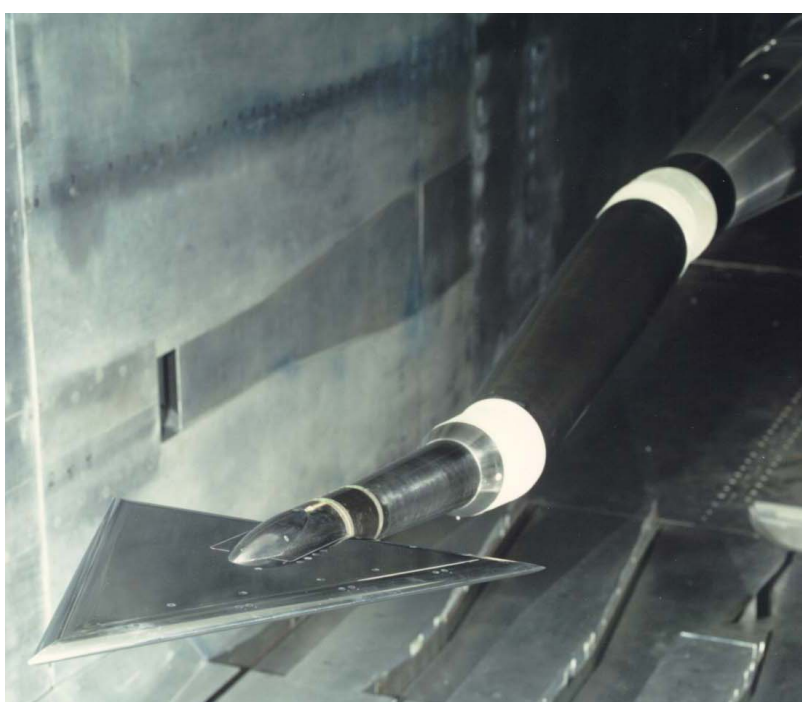

Figure 2: NASA $65^{\circ}$ delta wing $(\Lambda=1.85)$ in the NTFwind tunnel at NASA Langley Research Center.

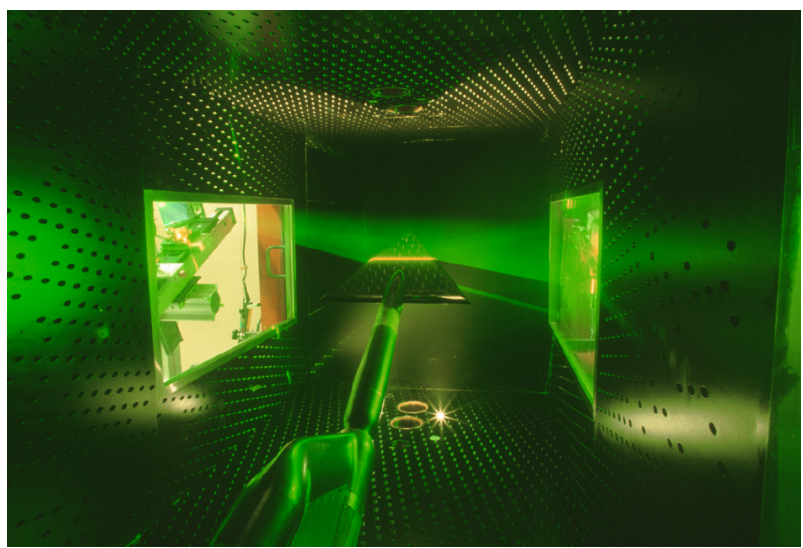

Figure 4: Model setup for PIV measurements in the Transonic Wind Tunnel Göttingen (TWG). The laser light sheet can be observed at approximately 50\% chord length. ${ }^{15}$ 

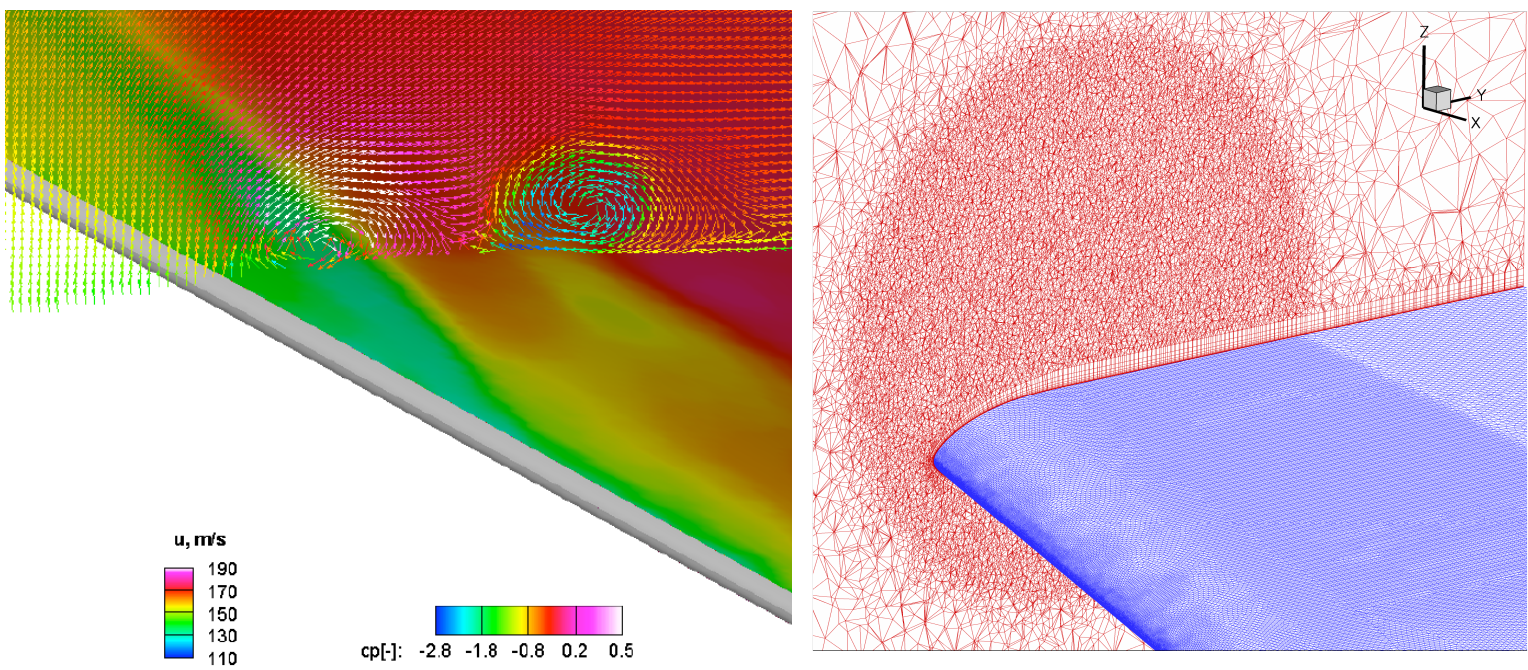

Figure 5: Pressure distribution on the upper surface Figure 6: Slice through the computational and PIV measurement at $\mathrm{x} / \mathrm{c}_{\text {ref }}=\mathbf{0 . 6} . \mathrm{M}=\mathbf{0 . 4}, \mathrm{Re}=$ unstructured grid. Fifteen prismatic layers to $3 \cdot 10^{6}, a=14^{\circ} .{ }^{15}$ PIV measurement shows the double resolve the boundary layer flow and a field primary vortex system. source to resolve the vortex flow over the wing.

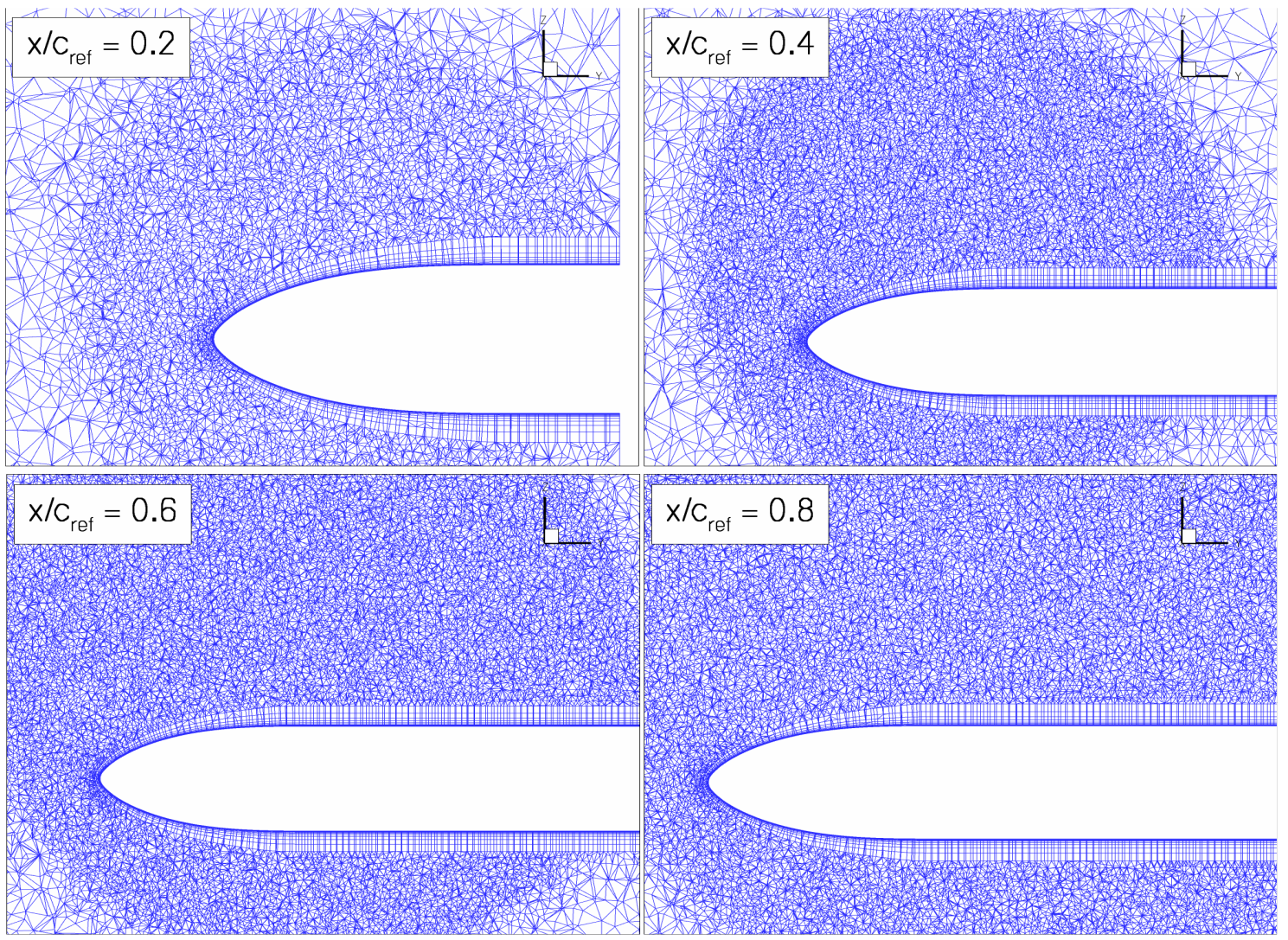

Figure 7: Slice through the computational unstructured grid at four different $x=$ constant positions. 


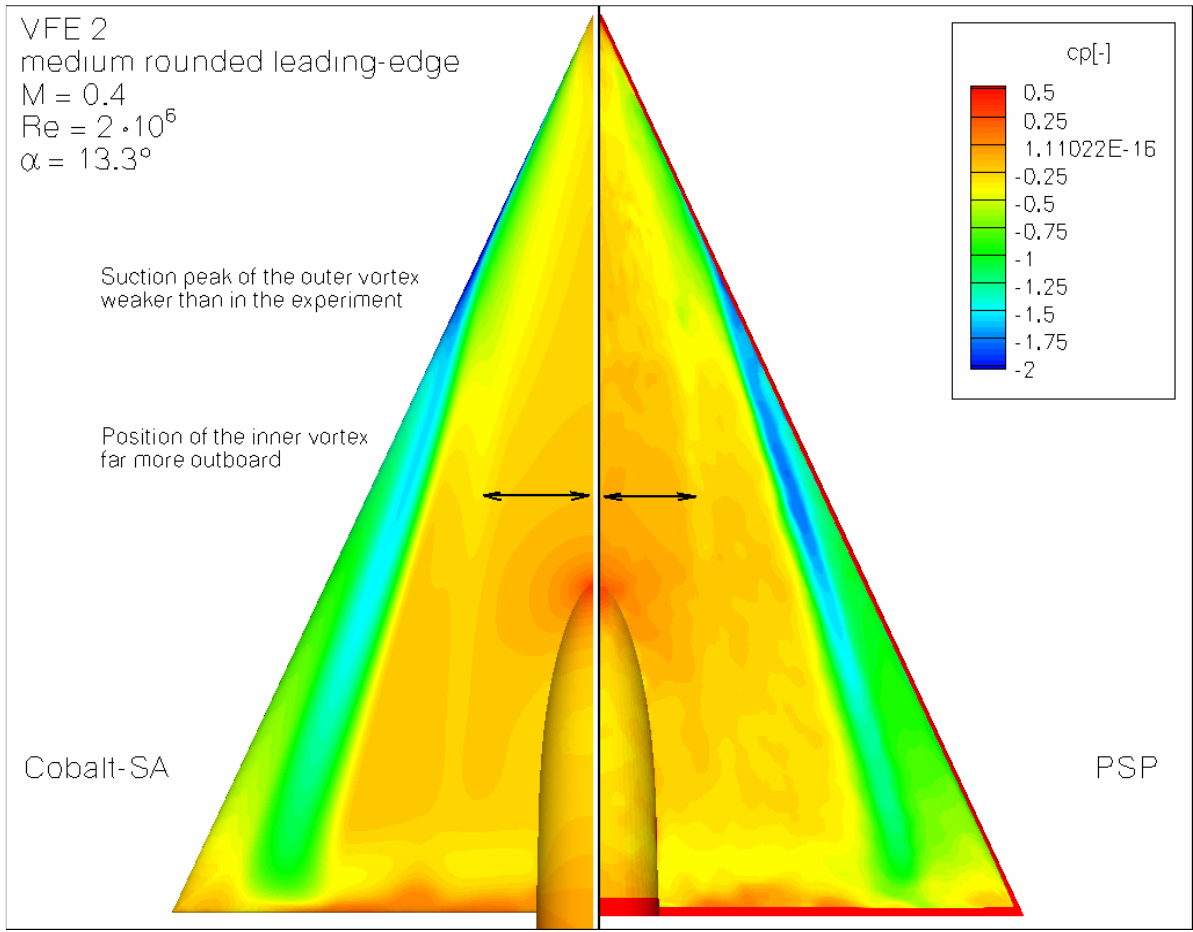

Figure 8: Pressure distribution on the upper surface of the wing. Comparison of CFD calculation and PSP measurement. $\operatorname{Re}=2 \cdot 10^{6}, \mathrm{M}=0.4, \alpha=$ $13.3^{\circ}$.

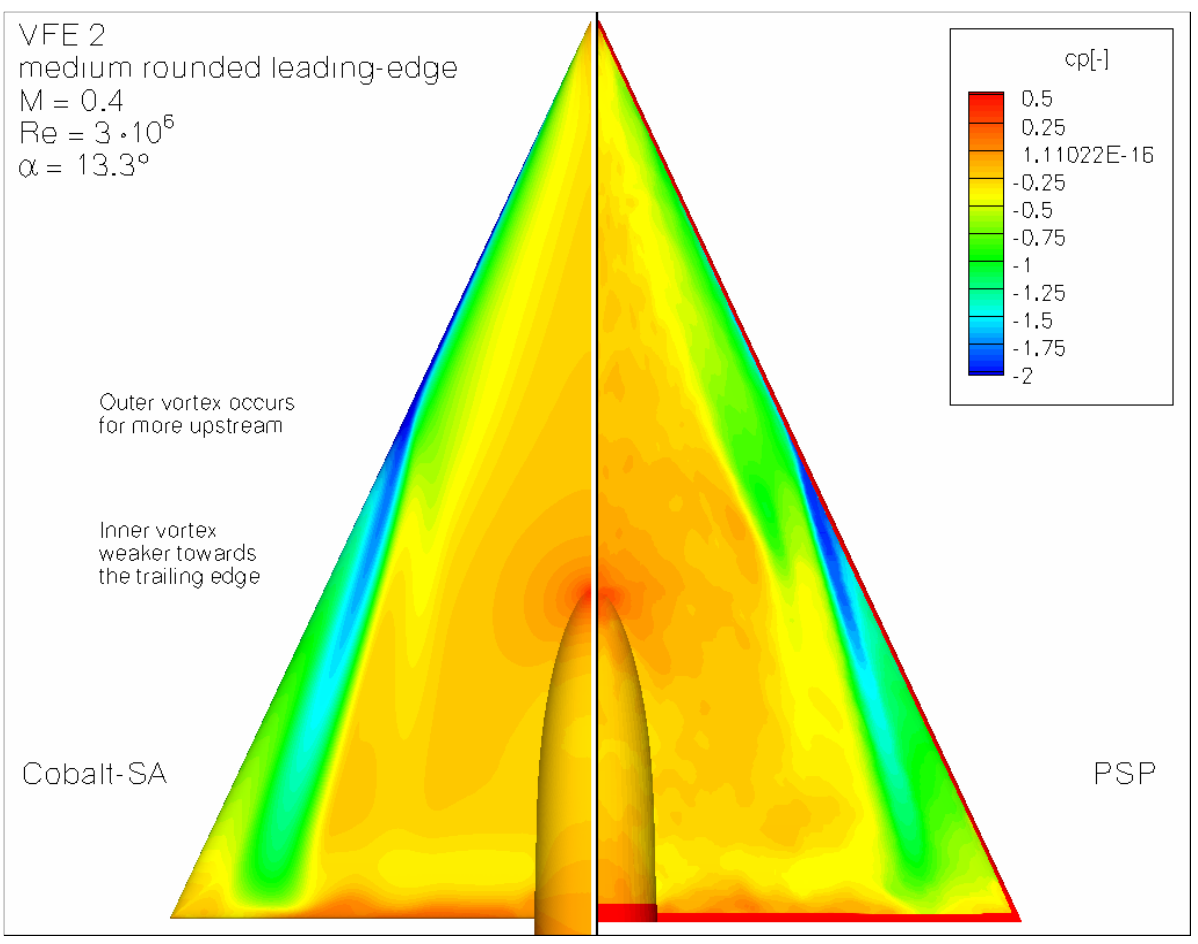

Figure 9: Pressure distribution on the upper surface of the wing. Comparison of CFD calculation and PSP measurement. $\operatorname{Re}=3 \cdot 10^{6}, \mathrm{M}=0.4, \alpha=$ $13.3^{\circ}$. 


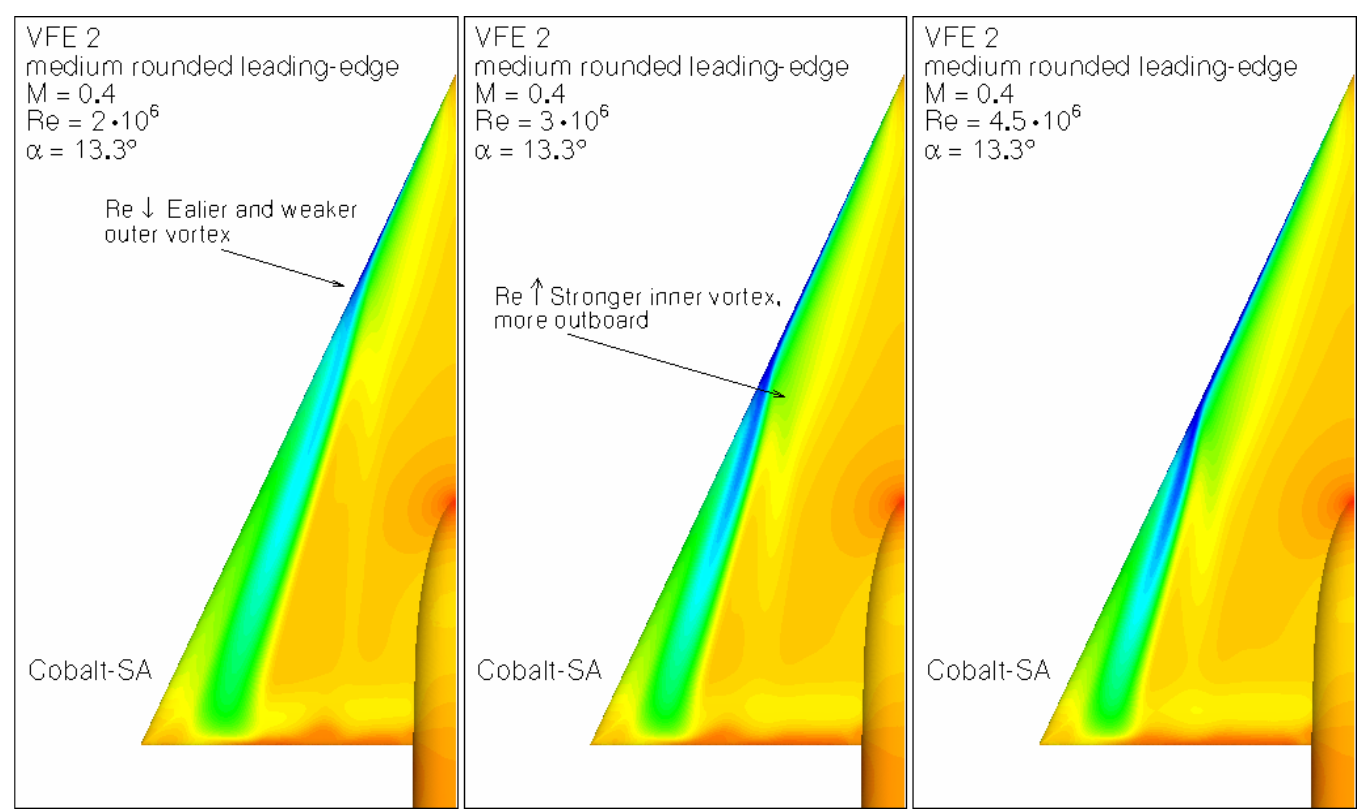

Figure 10: Pressure distribution on the upper surface of the wing. Comparison of CFD simulations at different Reynolds numbers, $M=0.4, \alpha=13.3^{\circ}$.
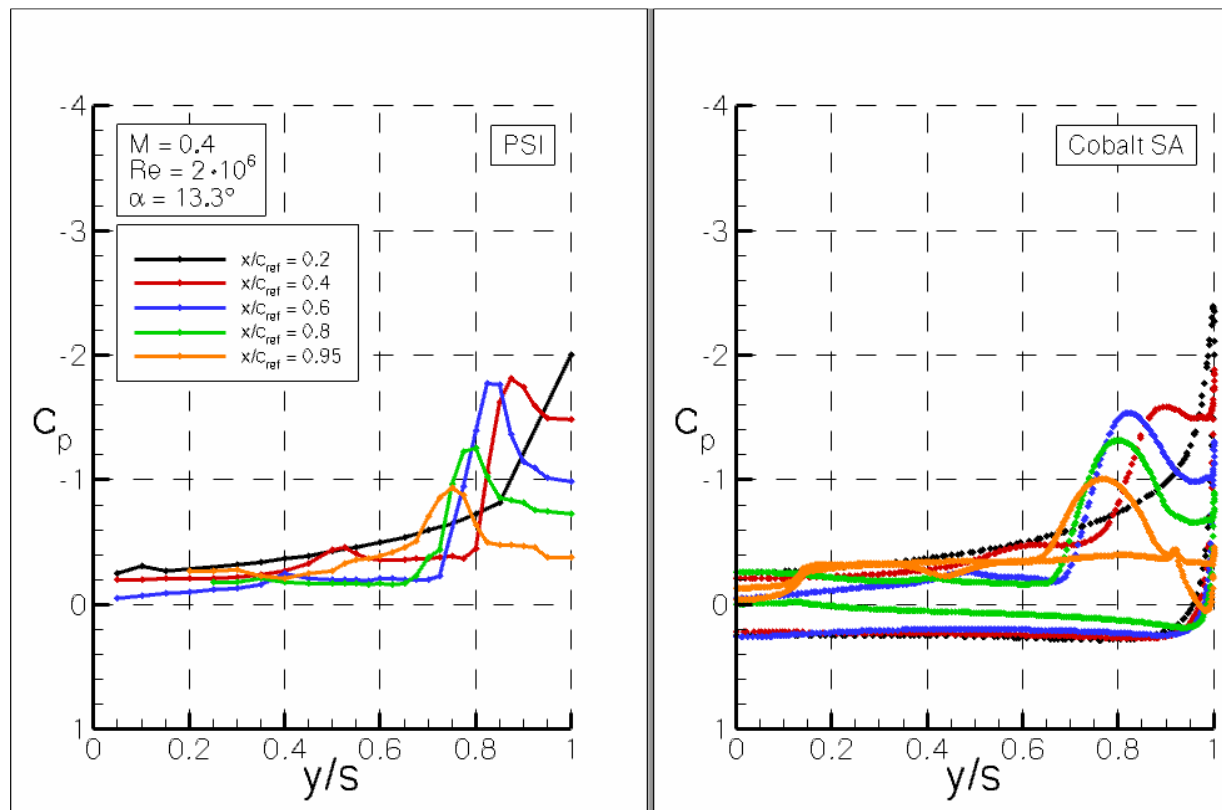

Figure 11: Pressure distribution at positions $x=$ const. Comparison of experiment and CFD calculation. $\operatorname{Re}=2 \cdot 10^{6}, M=0.4, \alpha=13.3^{\circ}$. 


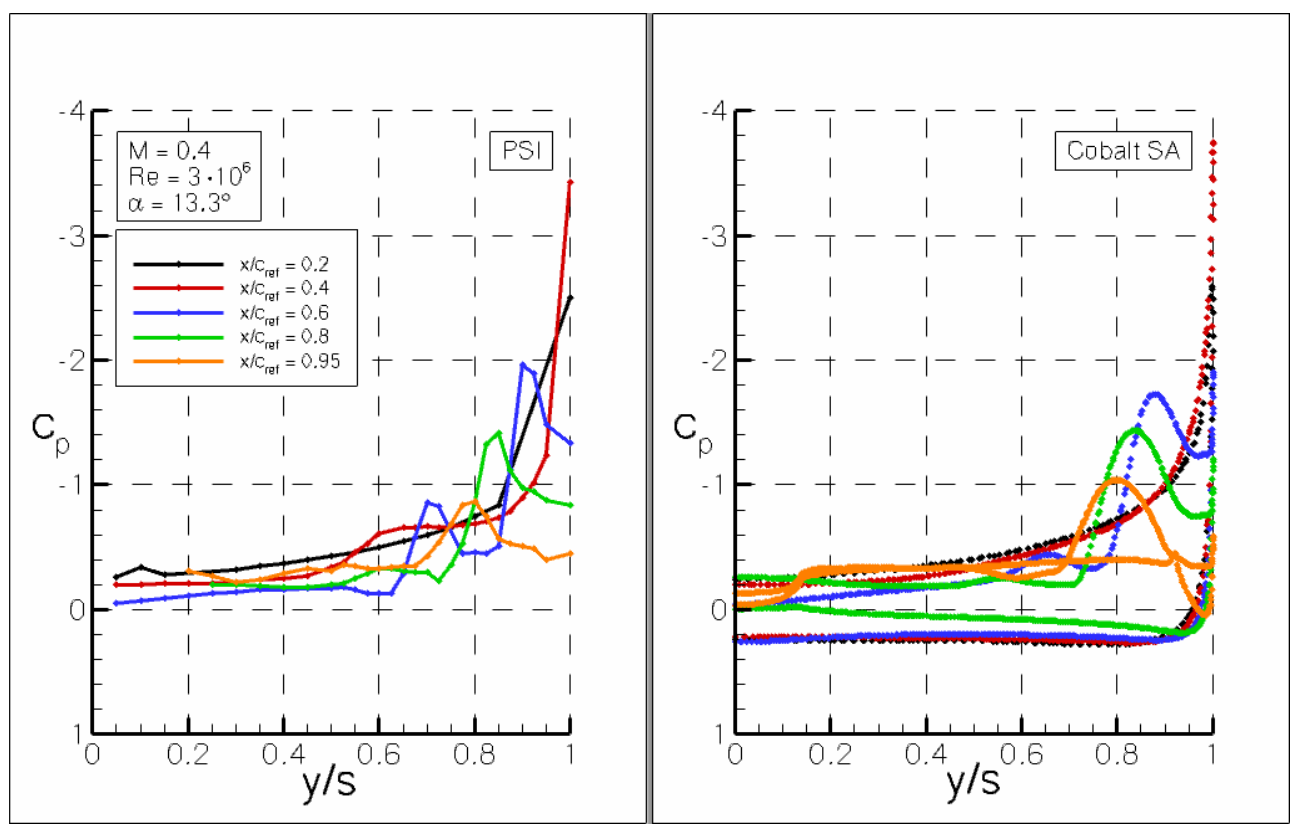

Figure 12: Pressure distribution at positions $x=$ const. Comparison of experiment and CFD calculation. $\operatorname{Re}=3 \cdot 10^{6}, M=0.4, \alpha=13.3^{\circ}$.

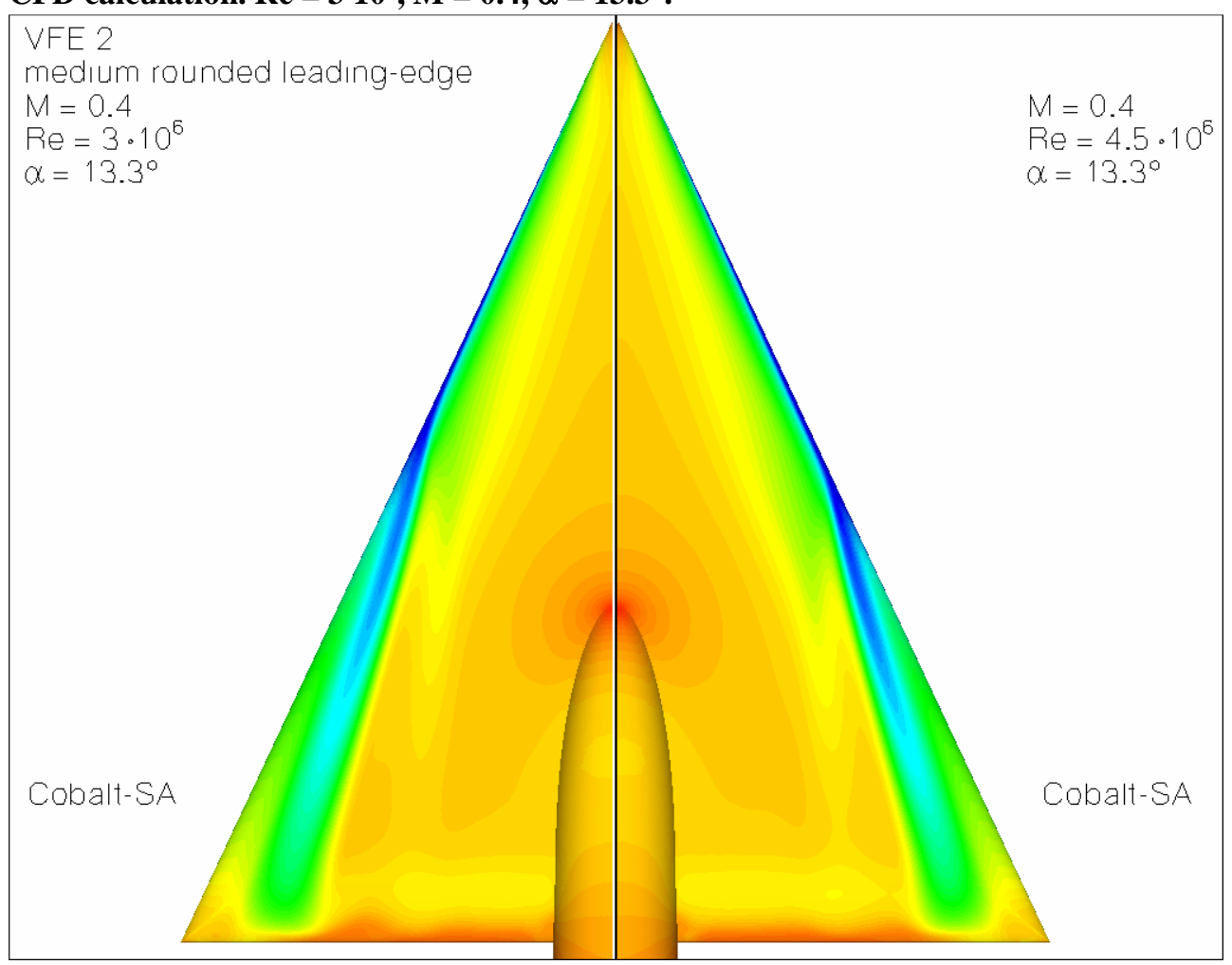

Figure 13: Pressure distribution on the upper surface of the wing. CFD calculation. Comparison $\operatorname{Re}=3 \cdot 10^{6}$ and $4 \cdot 5 \cdot 10^{6}$ at $M=0.4$ and $\alpha=13.3^{\circ}$. 


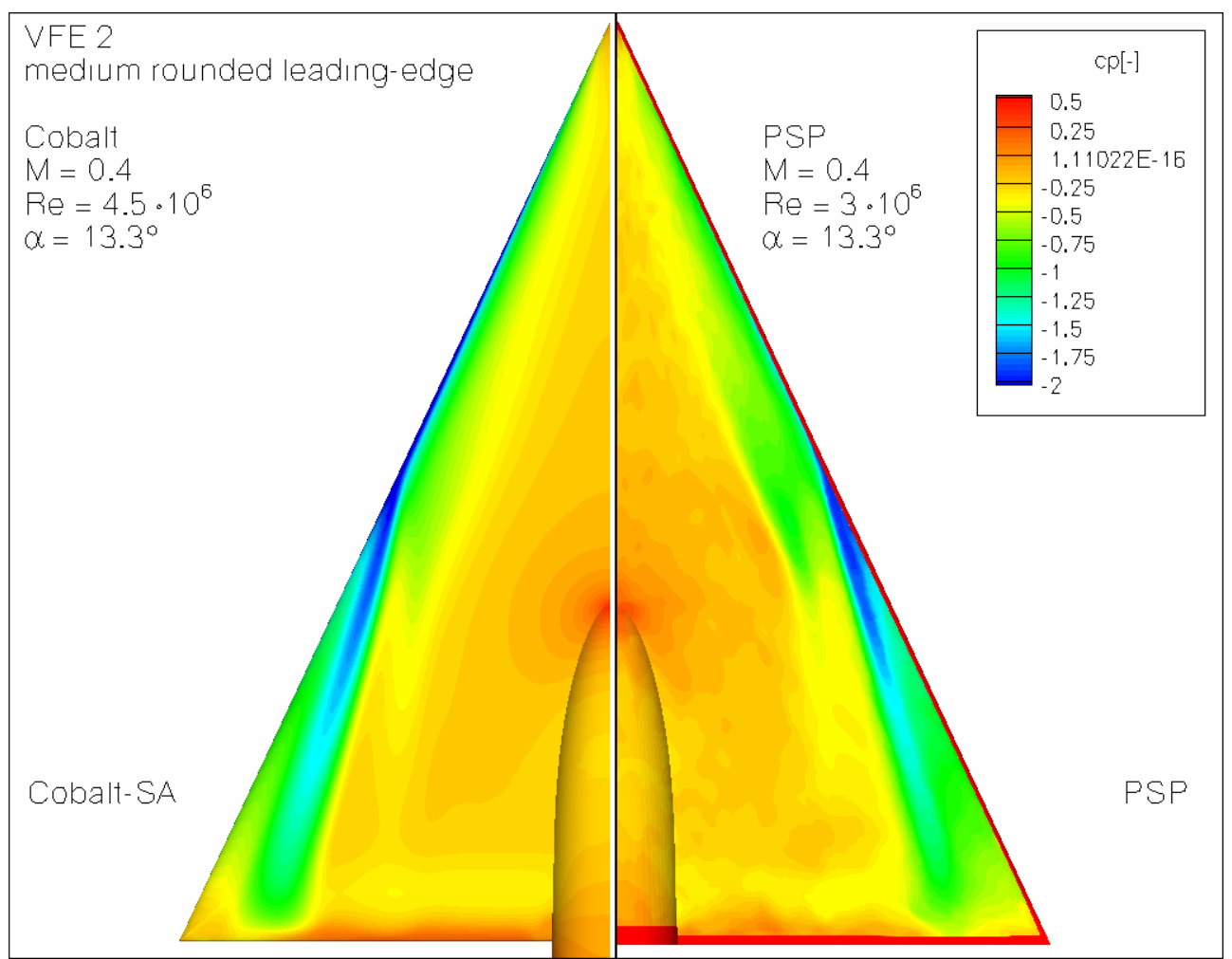

Figure 14: Pressure distribution on the upper surface of the wing. Comparison of CFD calculation $\left(\operatorname{Re}=4 \cdot 5 \cdot 10^{6}\right)$ and PSP measurement $\left(\operatorname{Re}=3 \cdot 10^{6}\right)$. $\mathrm{M}=\mathbf{0 . 4}, \alpha=13.3^{\circ}$.

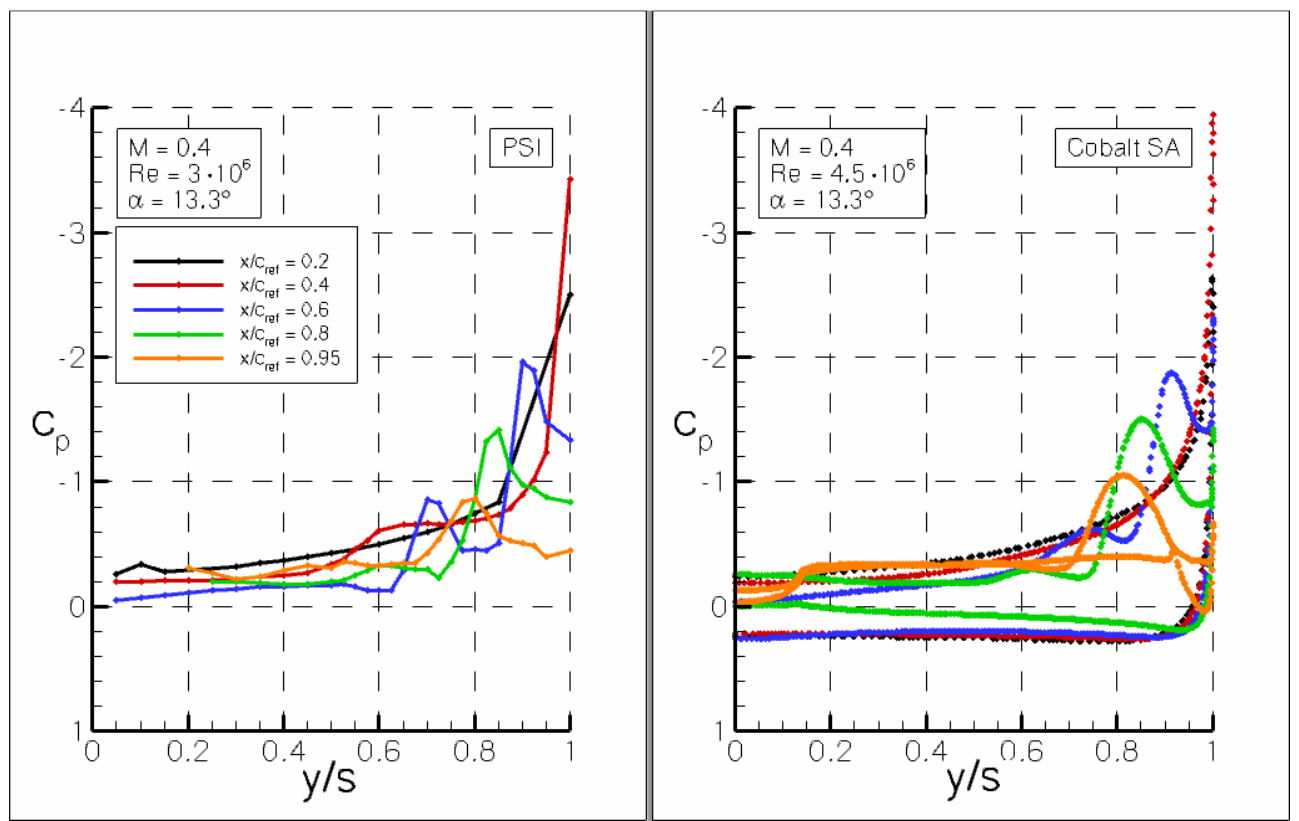

Figure 15: Pressure distribution at positions $x=$ const. Comparison of experiment $\left(\operatorname{Re}=3 \cdot 10^{6}\right)$ and $C F D$ calculation $\left(\operatorname{Re}=4.5 \cdot 10^{6}\right) . \mathrm{M}=0.4, \alpha=13.3^{\circ}$. 


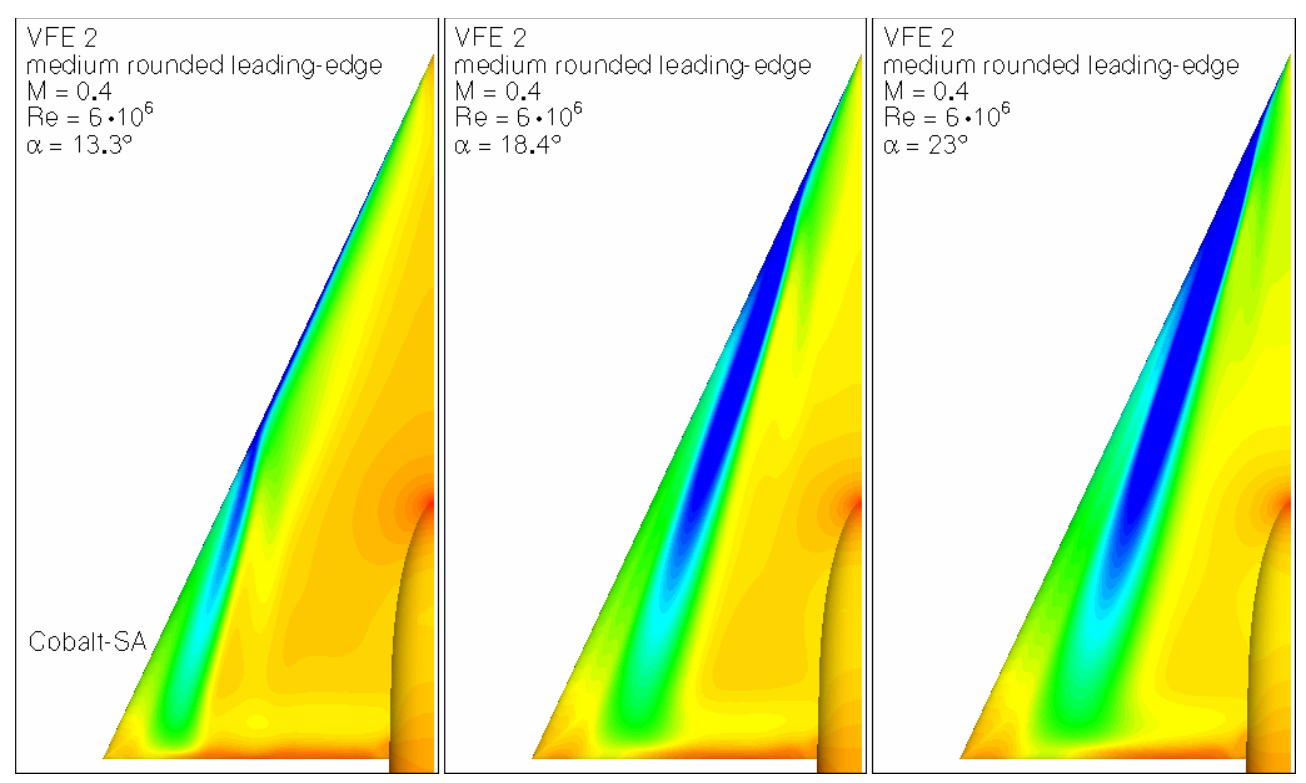

Figure 16: Pressure distribution on the upper surface of the wing. Comparison of CFD simulations at different angles of attack at Reynolds numbers $\operatorname{Re}=6 \cdot 10^{6}$.

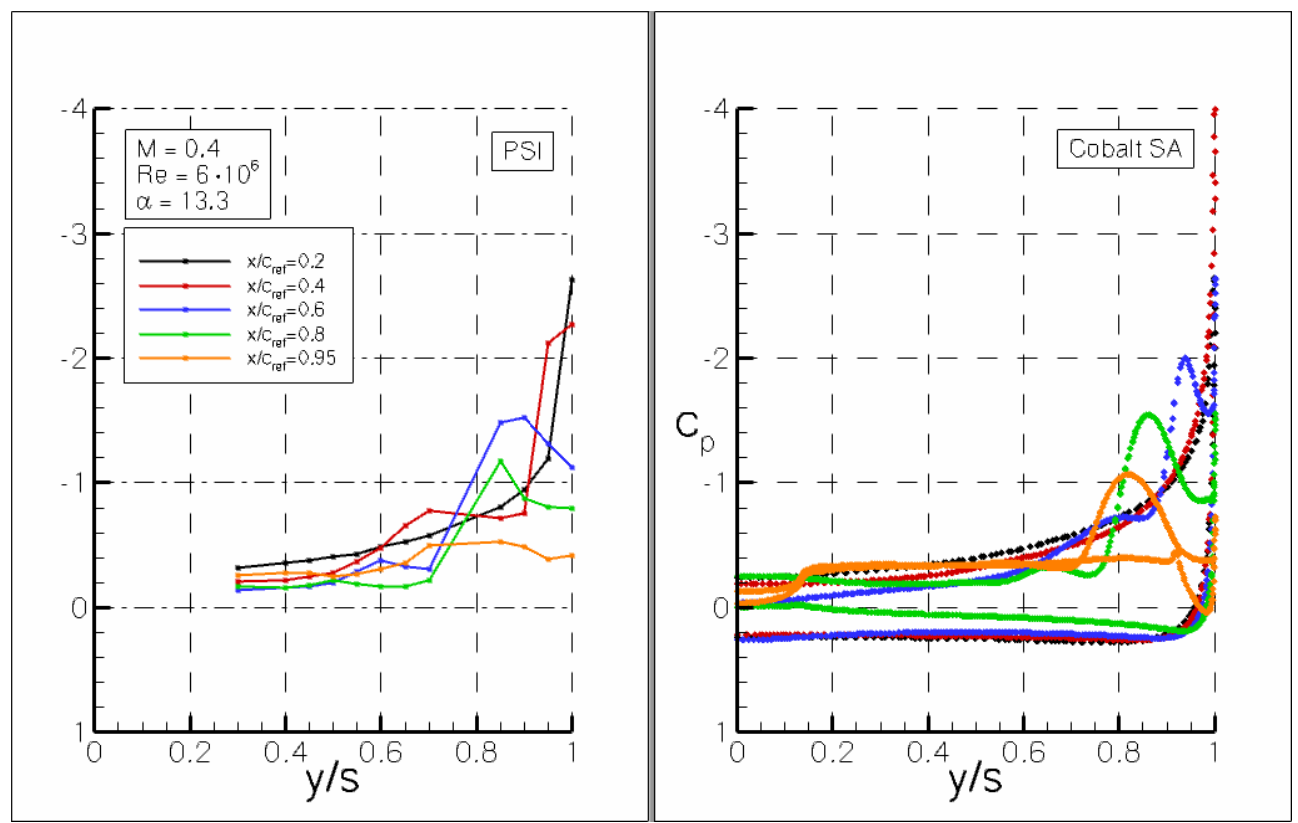

Figure 17: Pressure distribution at positions $x=$ const. Comparison of experiment $(\operatorname{Re}$ $\left.=6 \cdot 10^{6}\right)$ and CFD calculation $\left(\operatorname{Re}=6 \cdot 10^{6}\right) . M=0.4, \alpha=13.3^{\circ}$. 


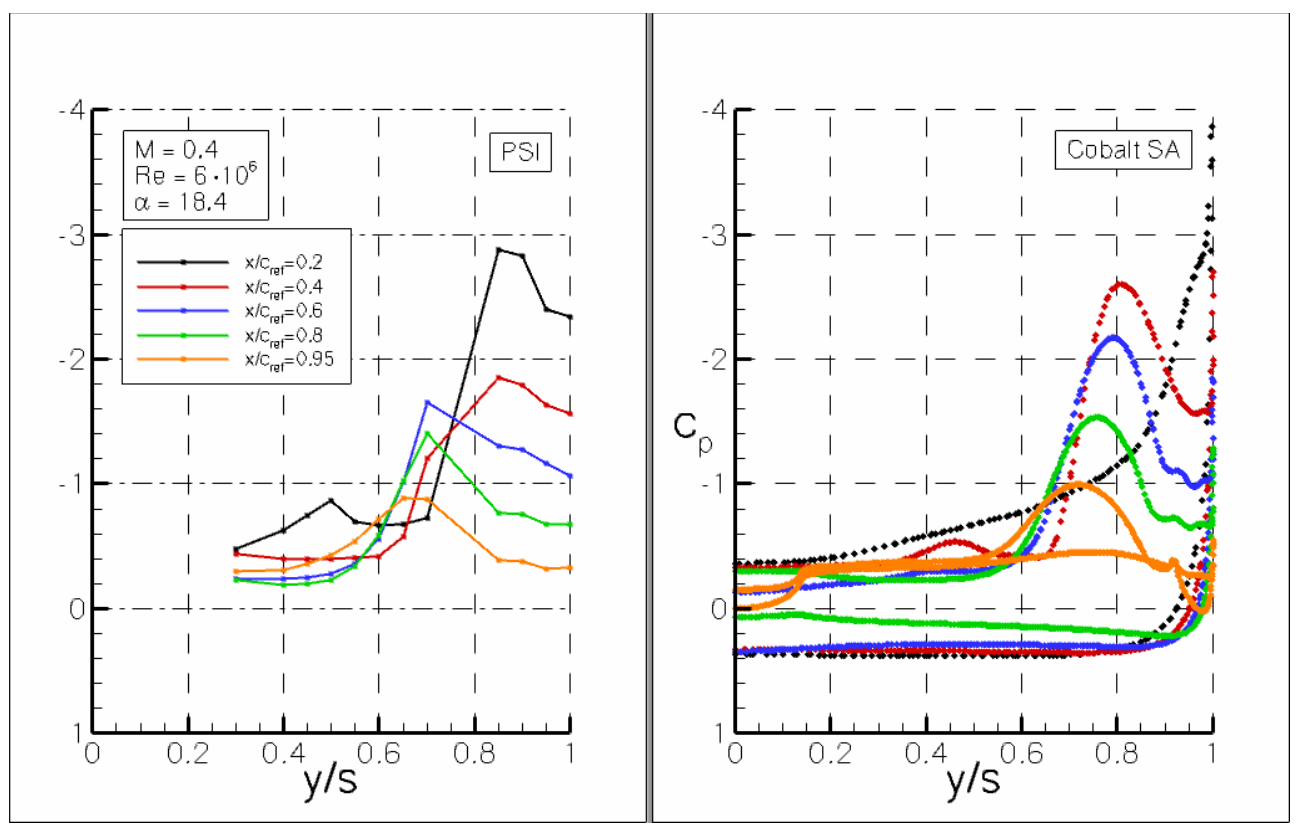

Figure 18: Pressure distribution at positions $x=$ const. Comparison of experiment $(\operatorname{Re}$ $\left.=6 \cdot 10^{6}\right)$ and $C F D$ calculation $\left(\operatorname{Re}=6 \cdot 10^{6}\right) . M=0.4, \alpha=18.4^{\circ}$.

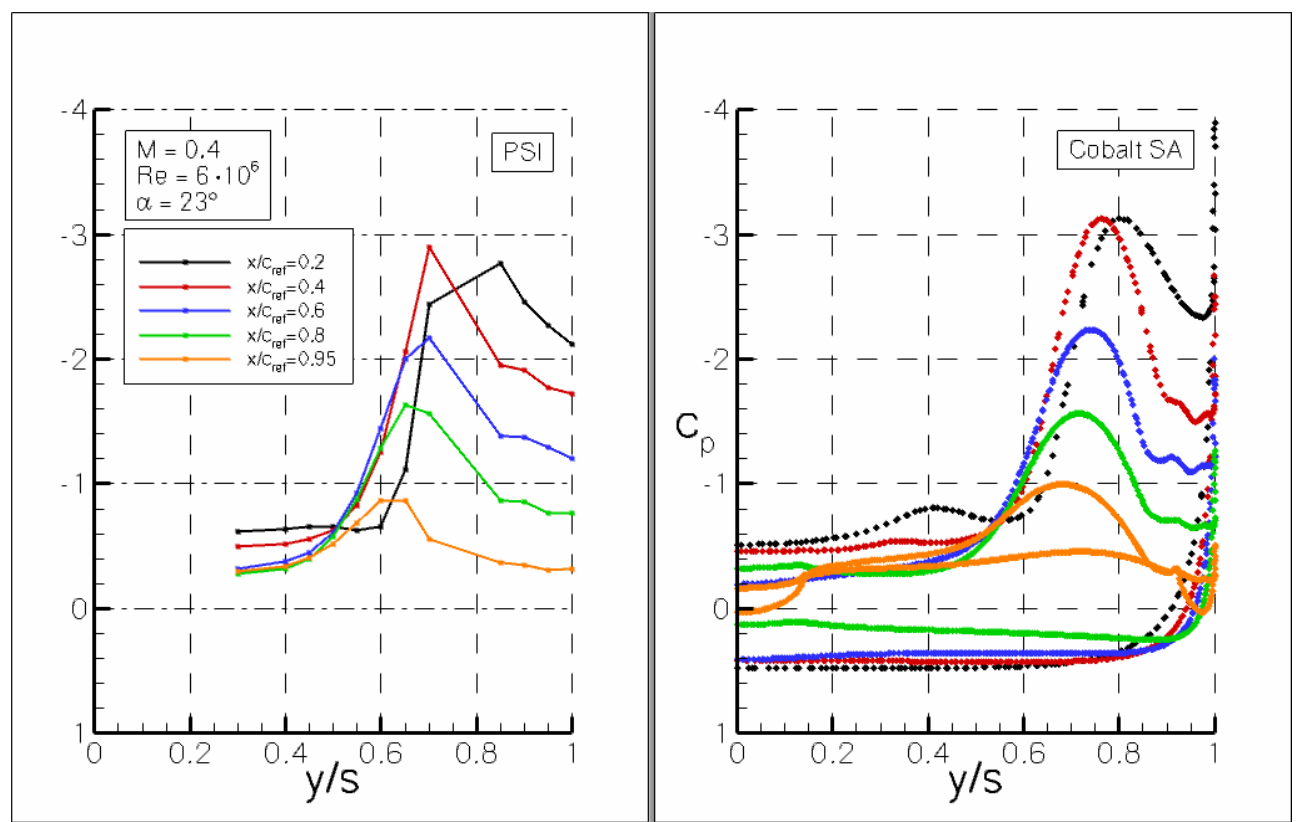

Figure 19: Pressure distribution at positions $x=$ const. Comparison of experiment (Re $\left.=6 \cdot 10^{6}\right)$ and $C F D$ calculation $\left(\operatorname{Re}=6 \cdot 10^{6}\right) . M=0.4, \alpha=23^{\circ}$. 


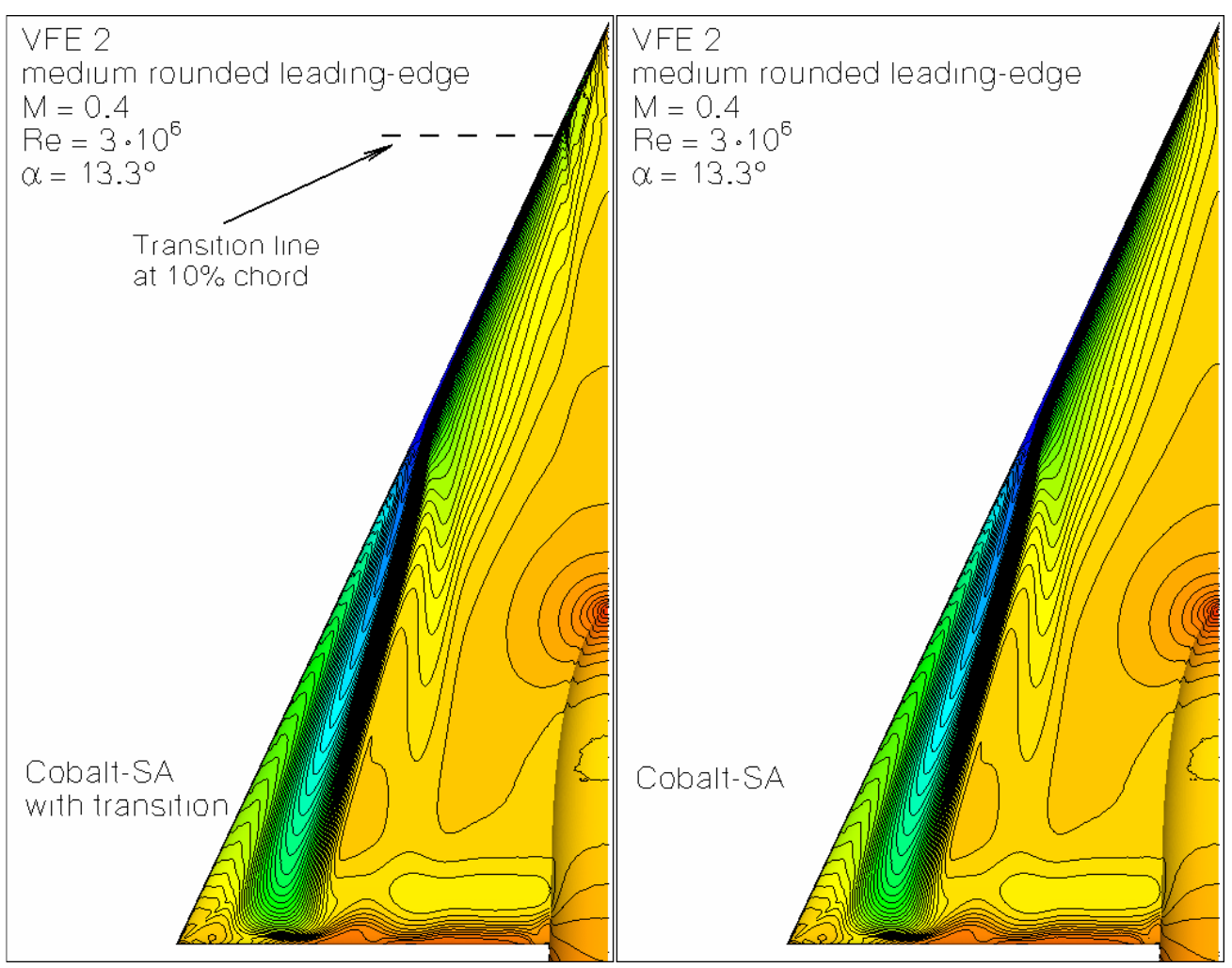

Figure 20: Pressure distribution on the upper surface of the wing. Comparison of CFD calculation $\left(\operatorname{Re}=3 \cdot 10^{6}\right.$ ) with and without transition line. $\mathrm{M}=\mathbf{0 . 4}$, $\alpha=13.3^{\circ}$.

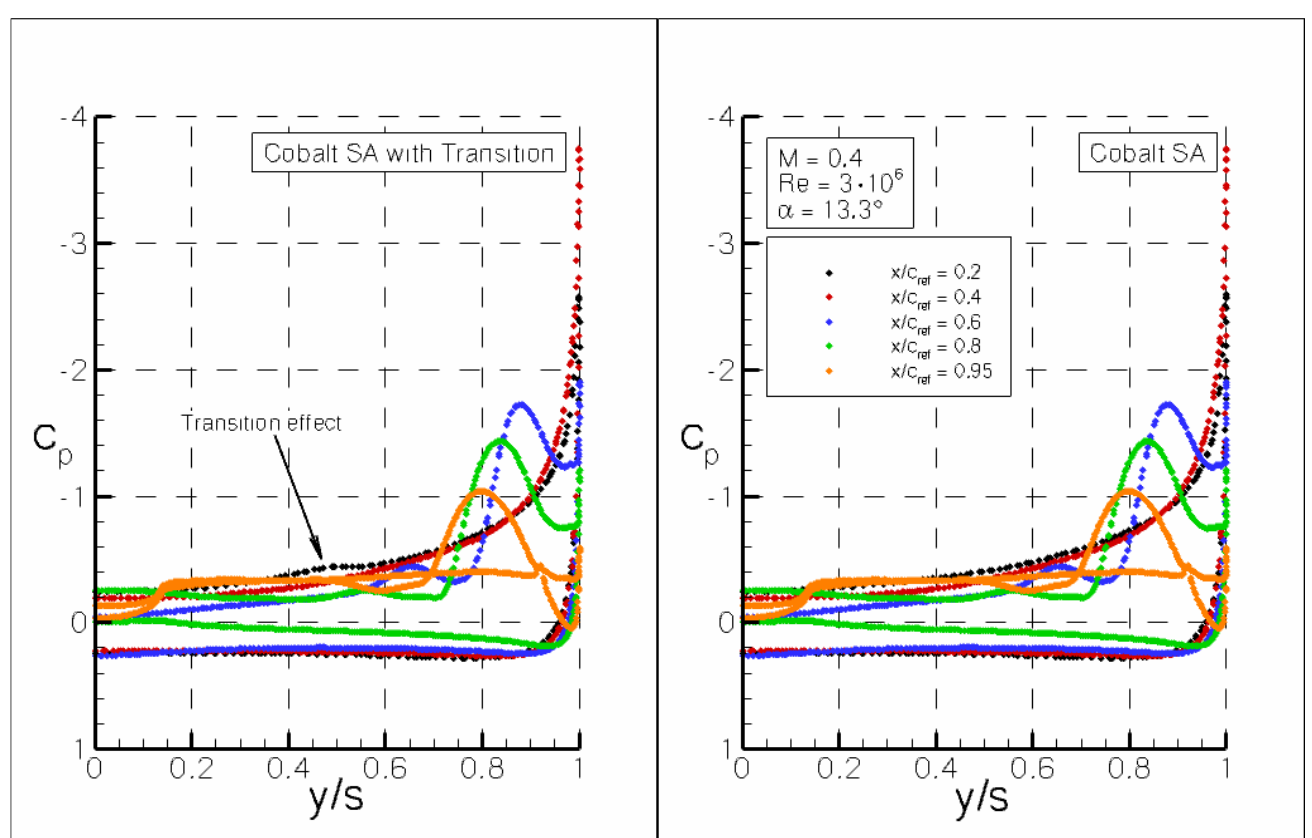

Figure 21: Pressure distribution at positions $x=$ const. Comparison of CFD calculation $\left(\operatorname{Re}=3 \cdot 10^{6}\right)$ with and without transition. $M=0.4, \alpha=13.3^{\circ}$. 


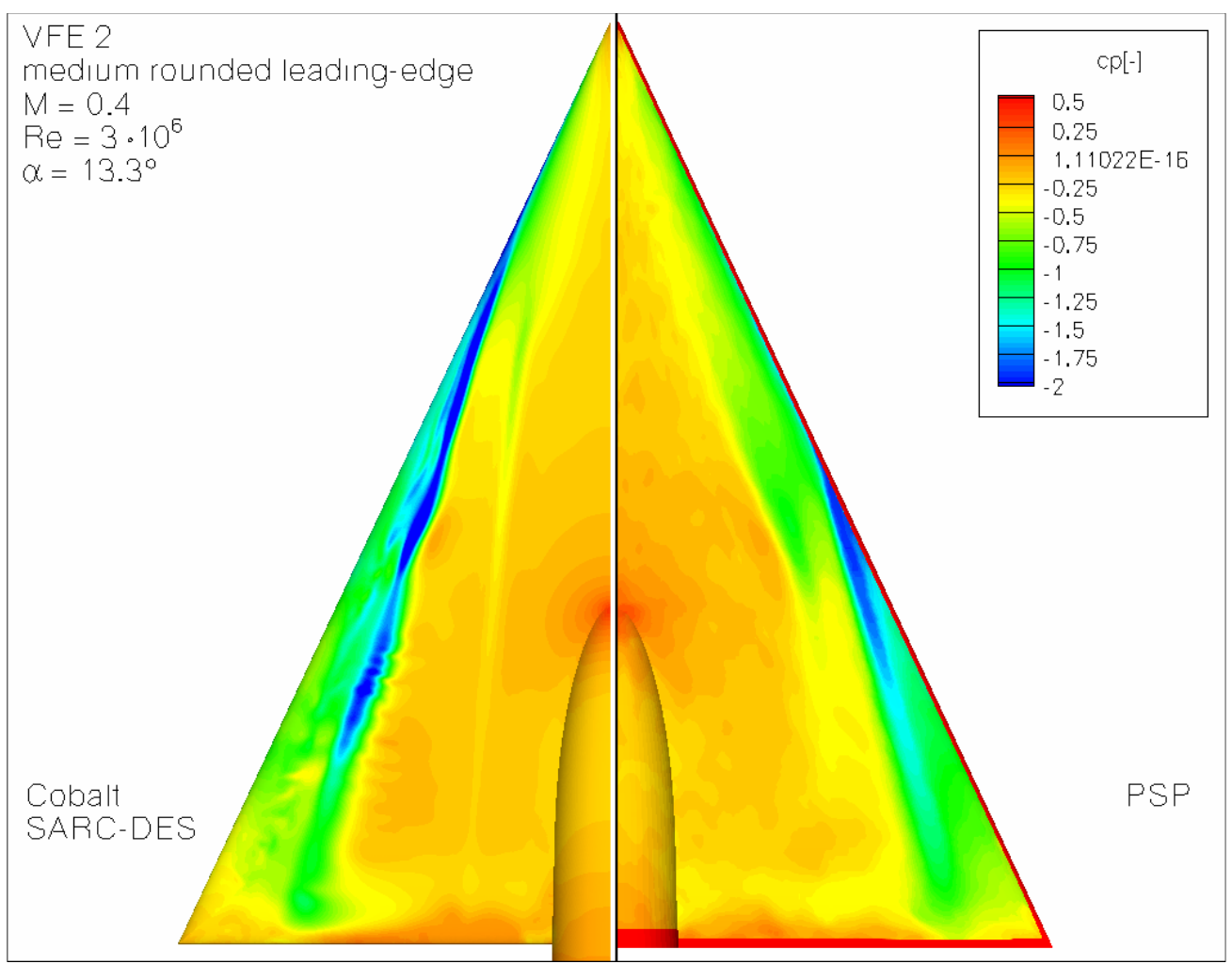

Figure 22: Pressure distribution on the upper surface of the wing. Comparison of CFD calculation (SARC-DES) and PSP measurement. $\operatorname{Re}=3 \cdot 10^{6}, \mathrm{M}=0.4, \alpha=13.3^{\circ}$.
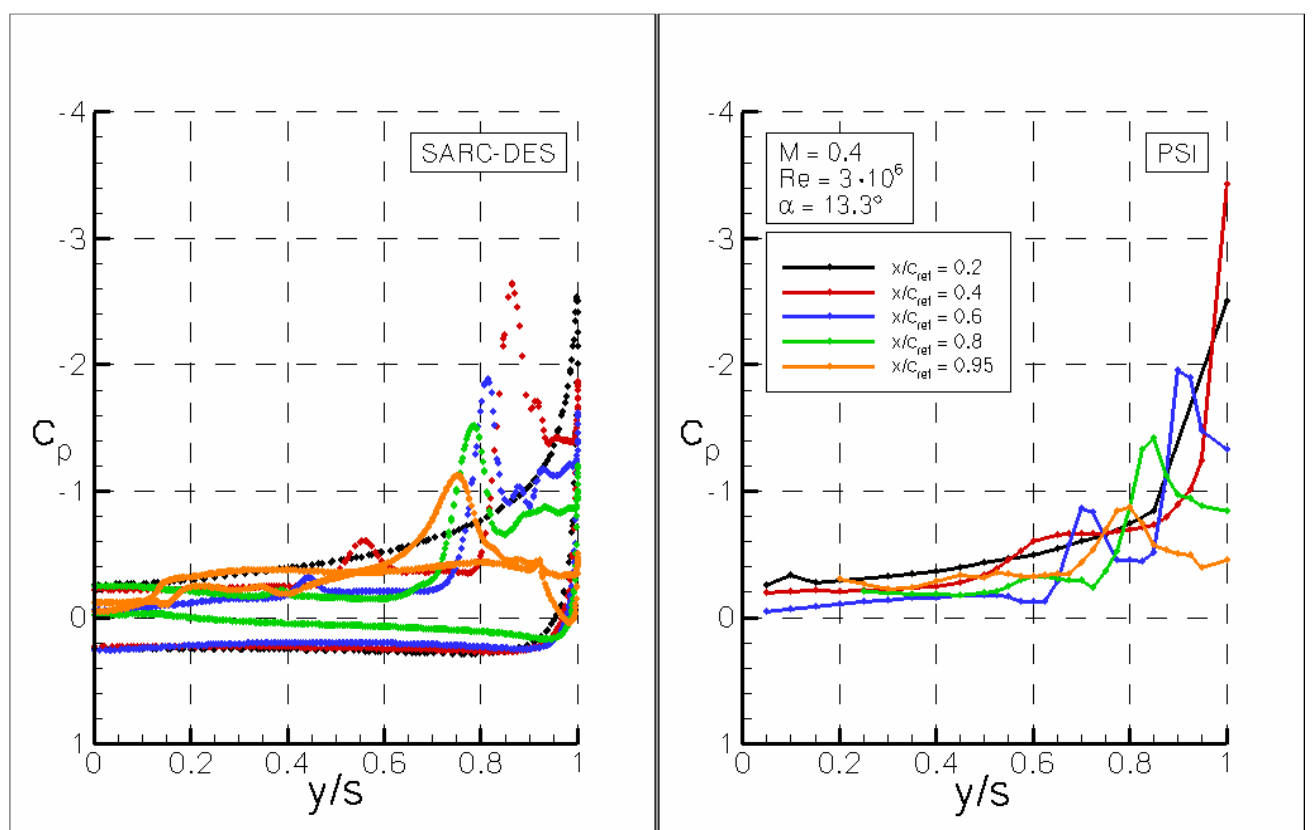

Figure 23: Pressure distribution at positions $x=$ const. Comparison of experiment and CFD calculation (SARC-DES). $\operatorname{Re}=3 \cdot 10^{6}, M=0.4, \alpha=13.3^{\circ}$. 


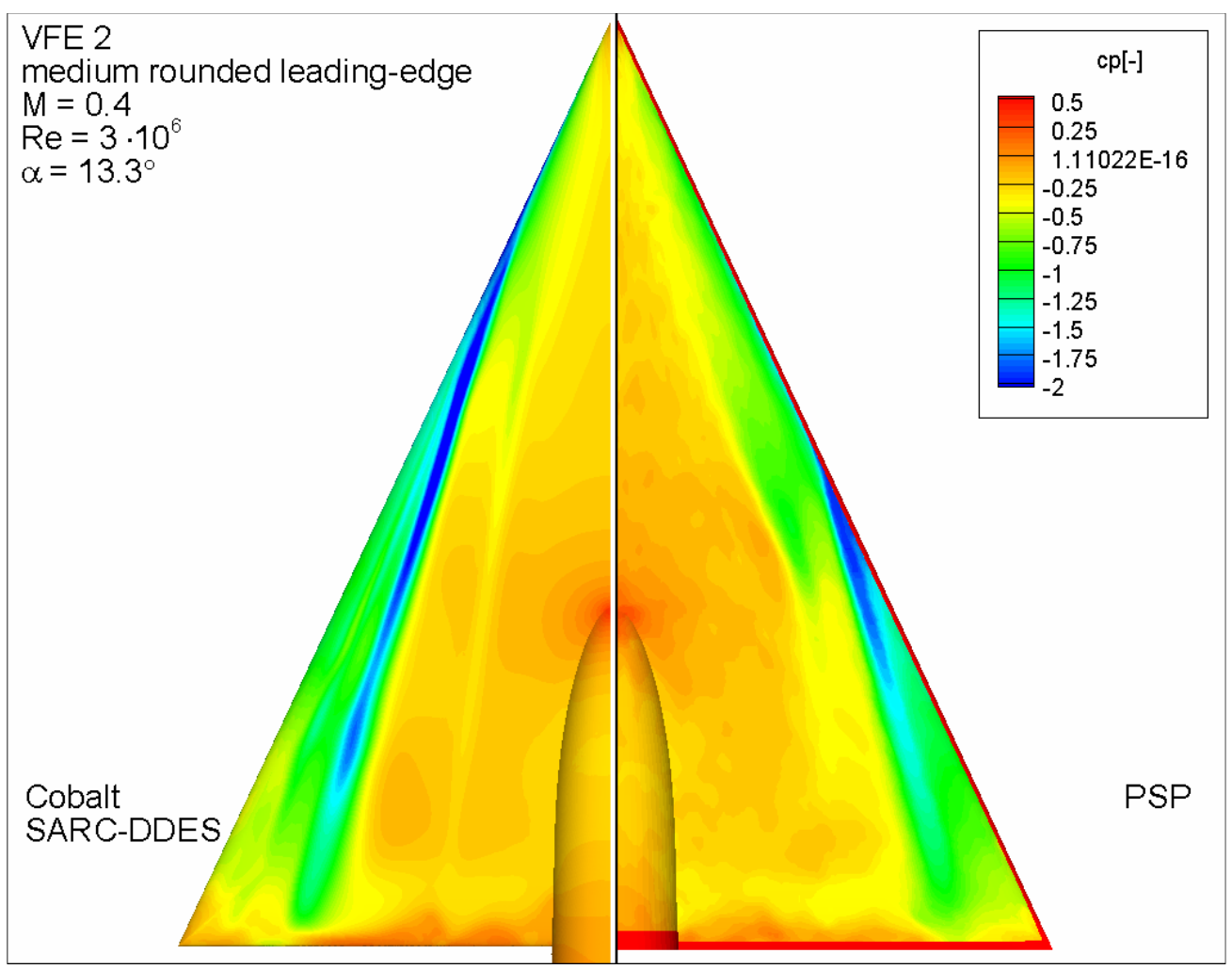

Figure 24: Pressure distribution on the upper surface of the wing. Comparison of CFD calculation (SARC-DDES) and PSP measurement. $\operatorname{Re}=3 \cdot 10^{6}, M=0.4, \alpha=13.3^{\circ}$.

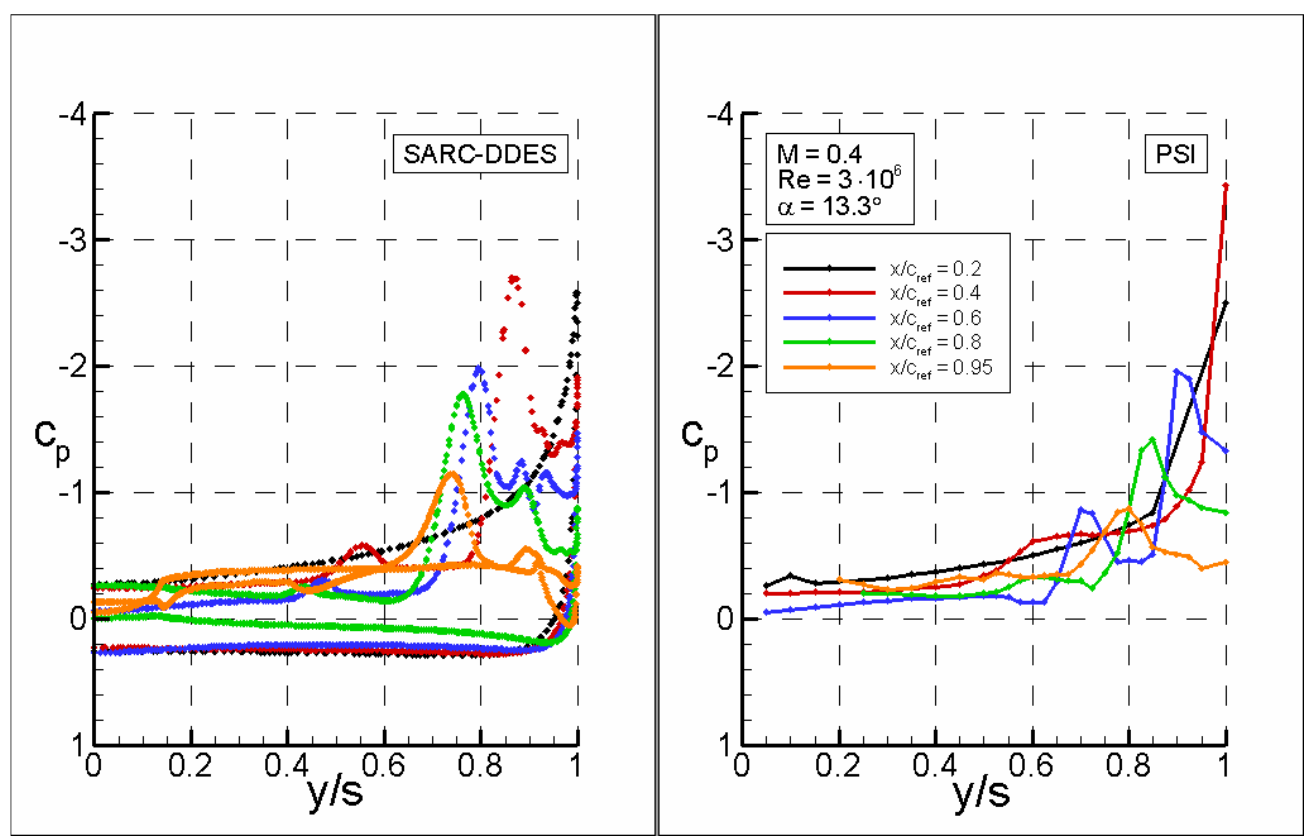

Figure 25: Pressure distribution at positions $x=$ const. Comparison of experiment and CFD calculation (SARC-DDES). $\operatorname{Re}=3 \cdot 10^{6}, \mathrm{M}=0.4, \alpha=13.3^{\circ}$. 


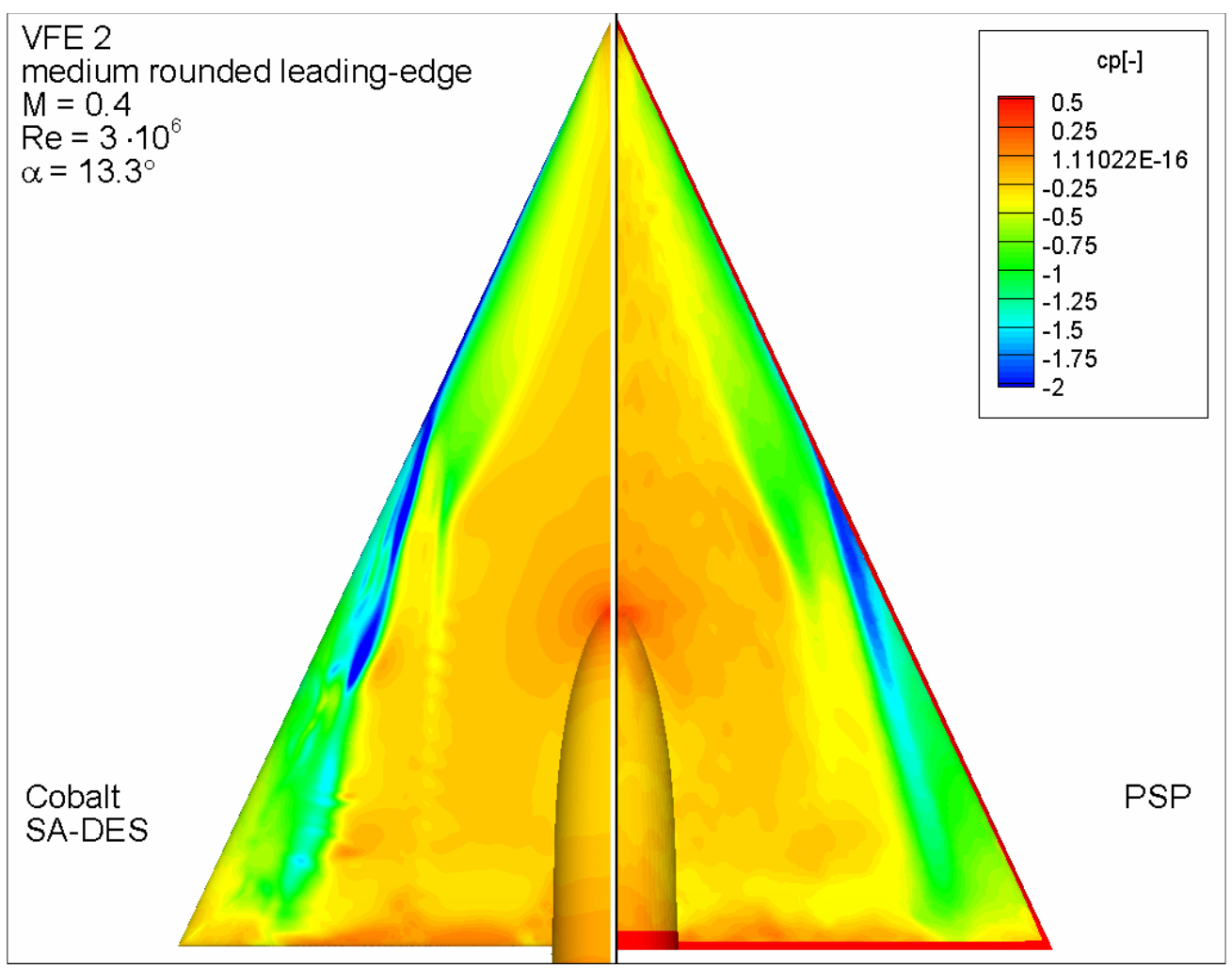

Figure 26: Pressure distribution on the upper surface of the wing. Comparison of CFD calculation (SA-DES) and PSP measurement. $\operatorname{Re}=3 \cdot 10^{6}, M=0.4, \alpha=13.3^{\circ}$.

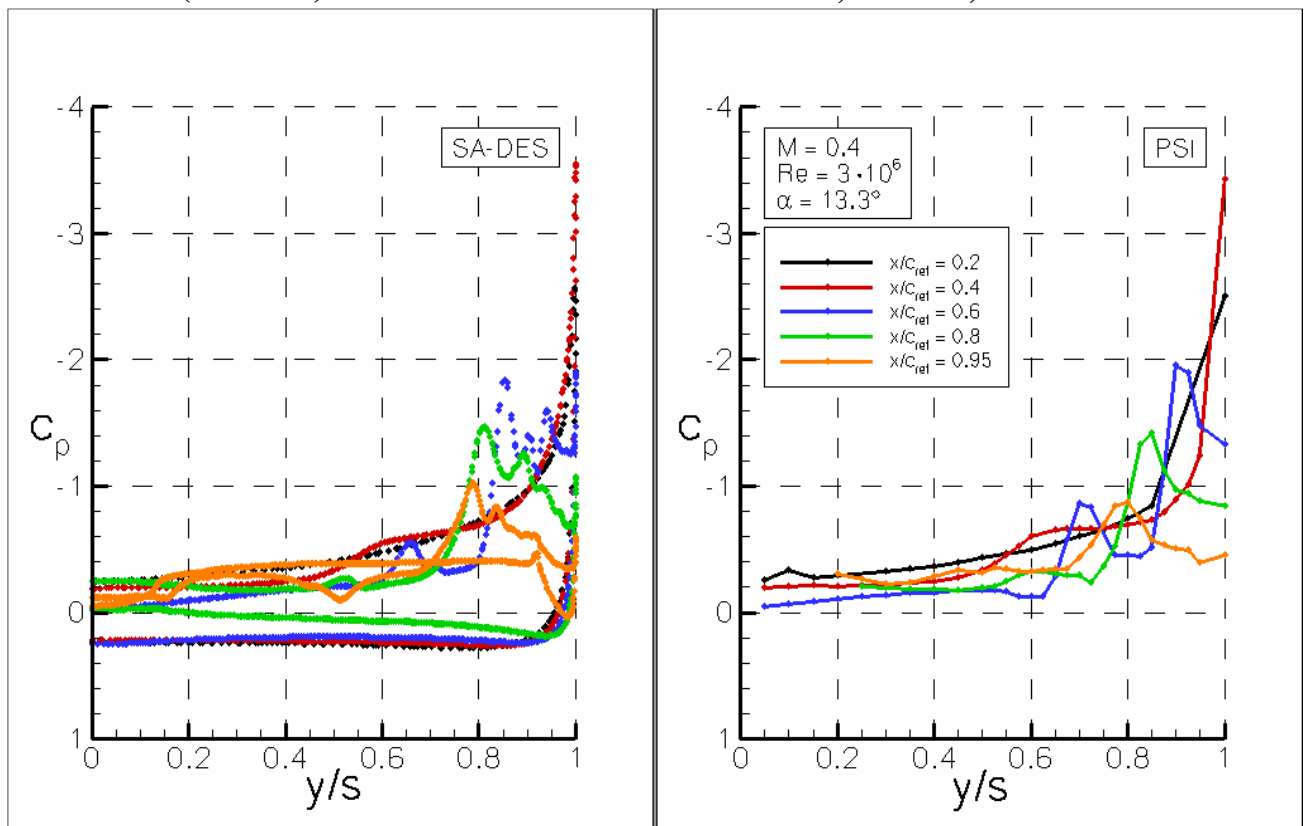

Figure 27: Pressure distribution at positions $x=$ const. Comparison of experiment and CFD calculation ( $S A-D E S)$. $R e=3 \cdot 10^{6}, M=0.4, \alpha=13.3^{\circ}$. 


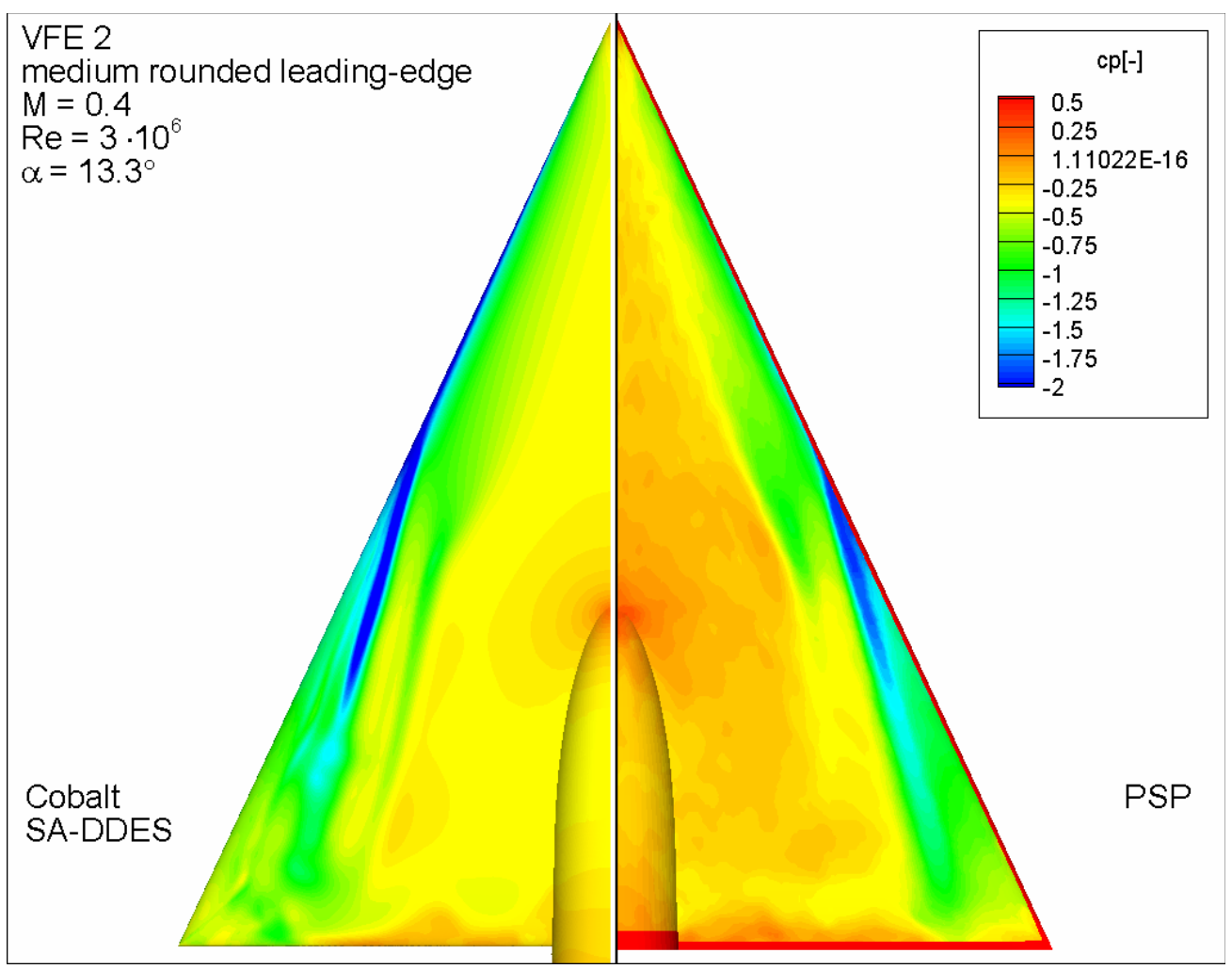

Figure 28: Pressure distribution on the upper surface of the wing. Comparison of CFD calculation (SA-DDES) and PSP measurement. $\operatorname{Re}=3 \cdot 10^{6}, M=0.4, \alpha=13.3^{\circ}$.

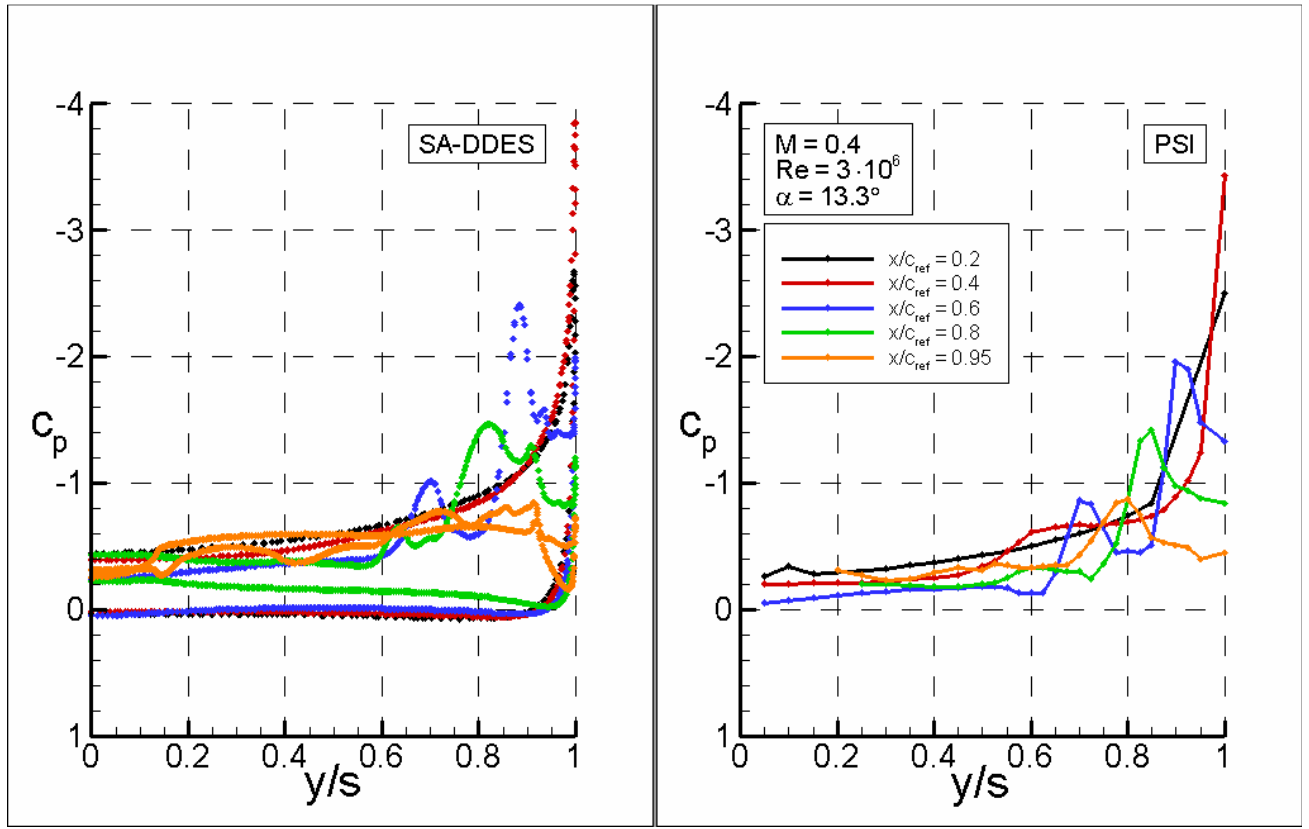

Figure 29: Pressure distribution at positions $x=$ const. Comparison of experiment and CFD calculation (SA-DDES). $\operatorname{Re}=3 \cdot 10^{6}, \mathrm{M}=0.4, \alpha=13.3^{\circ}$. 


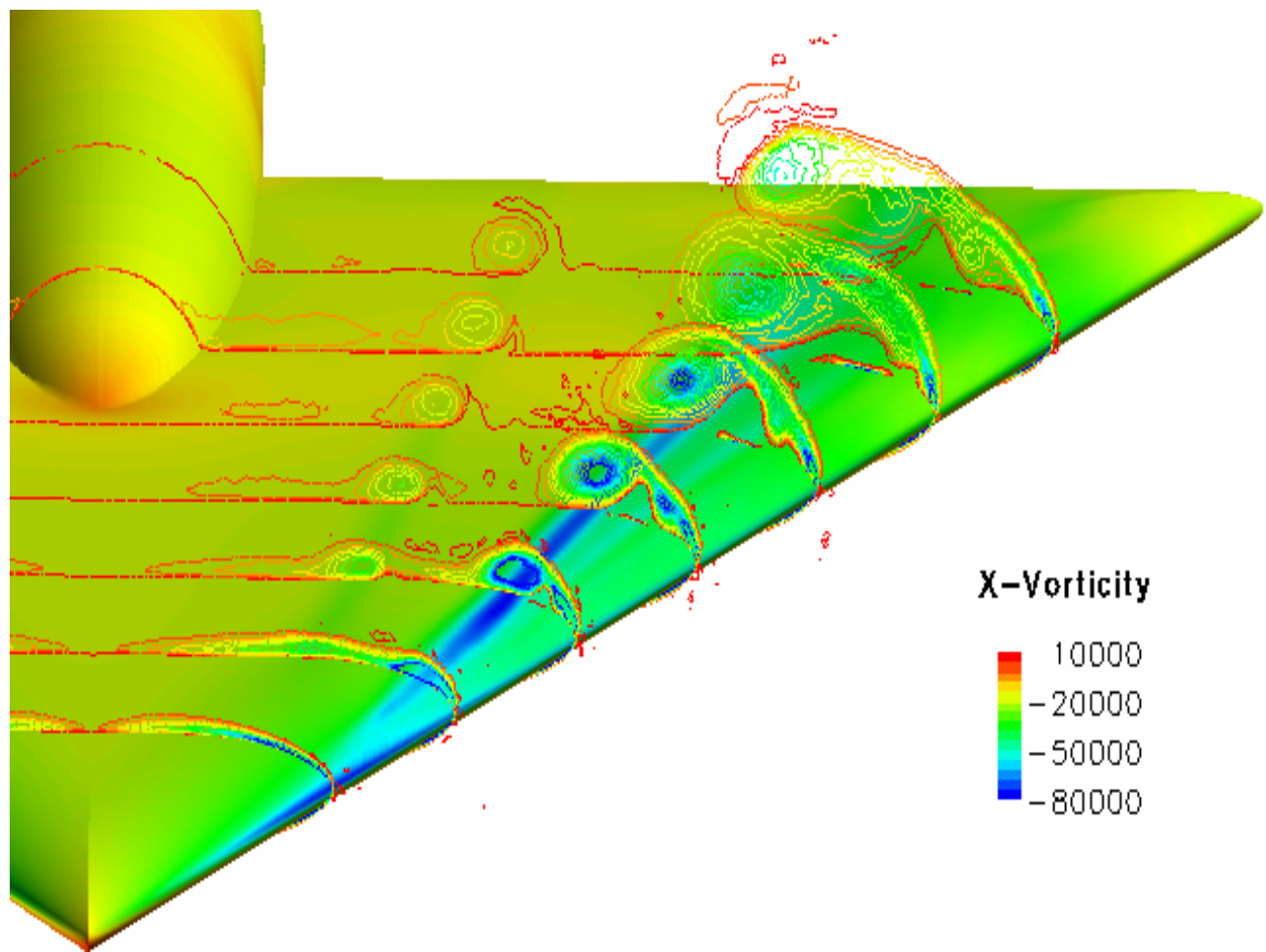

Figure 30: Surface pressure distribution and $x$-vorticity at positions $x=$ const. $\operatorname{Re}=3 \cdot 10^{6}, M=0.4, \alpha=13.3^{\circ}$.

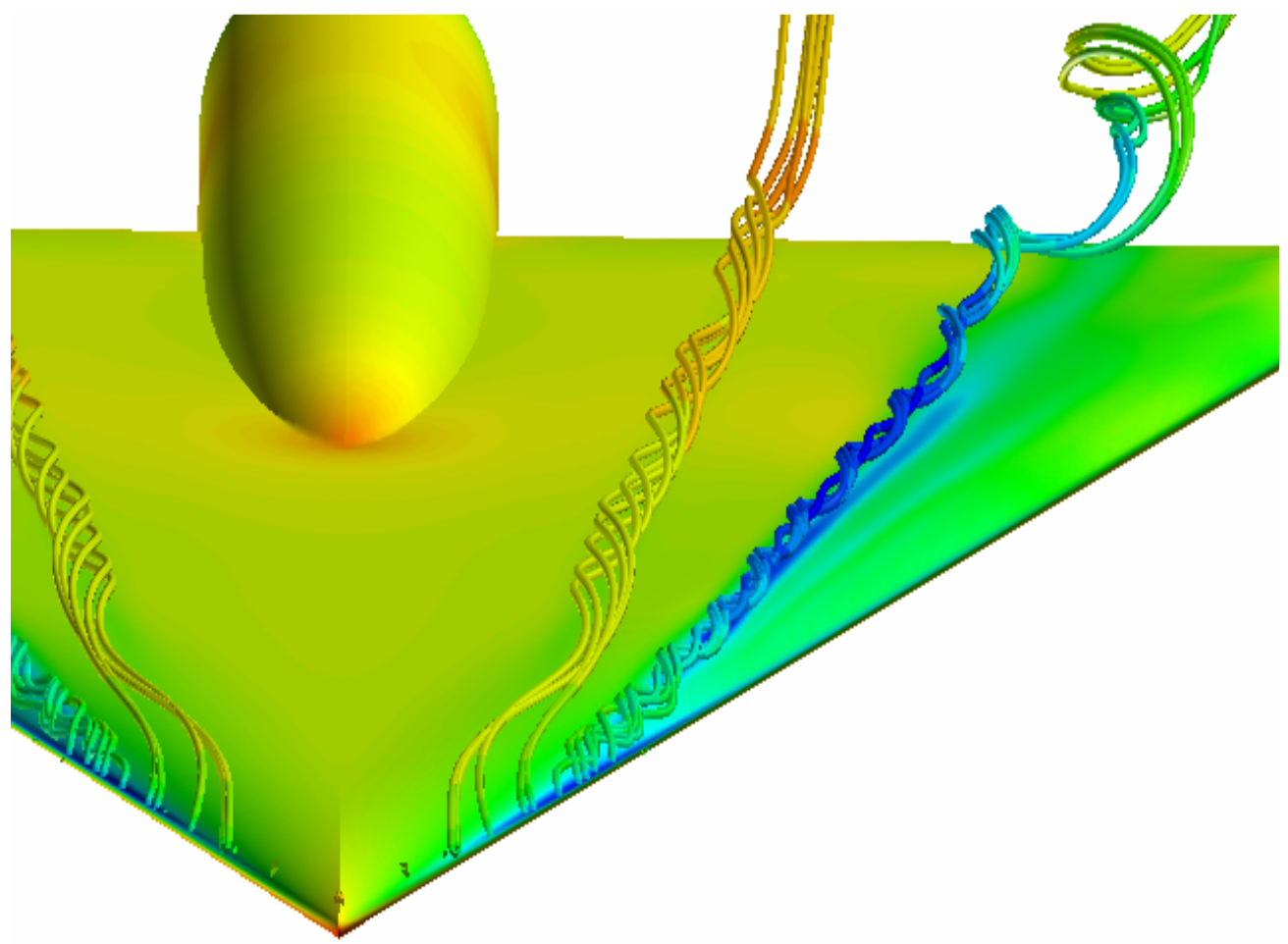

Figure 31: Streamlines and pressure distribution. $\operatorname{Re}=3 \cdot 10^{6}, M=0.4, \alpha=13.3^{\circ}$. 


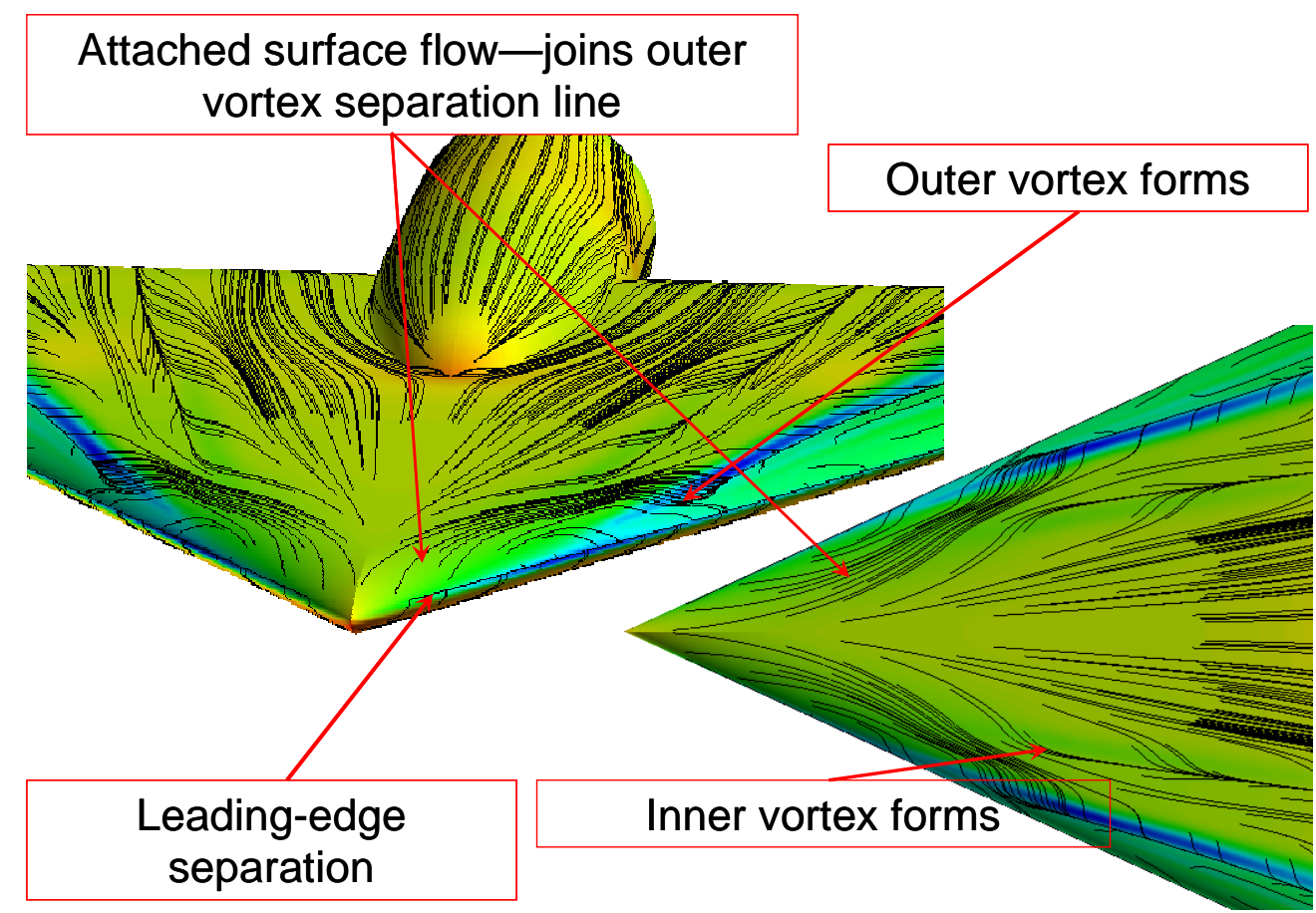

Figure 32: Skin friction lines and pressure distribution. $\operatorname{Re}=3 \cdot 10^{6}, \mathrm{M}=0.4, \alpha=13.3^{\circ}$. 